\title{
Convection above the Labrador Continental Slope
}

\author{
JÉrôme Cuny And Peter B. Rhines \\ University of Washington, Seattle, Washington \\ FRIEDRICH SCHOTT \\ Institut für Meereskunde, Kiel, Germany \\ JOHN LAZIER \\ Bedford Institute of Oceanography, Halifax, Nova Scotia, Canada
}

(Manuscript received 4 September 2003, in final form 26 July 2004)

ABSTRACT

\begin{abstract}
The Labrador Sea is one of the few regions of the World Ocean where deep convection takes place. Several moorings across the Labrador continental slope just north of Hamilton Bank show that convection does take place within the Labrador Current. Mixing above the lower Labrador slope is facilitated by the onshore along-isopycnal intrusions of low-potential-vorticity eddies that weaken the stratification, combined with baroclinic instability that sustains slanted mixing while restratifying the water column through horizontal fluxes. Above the shelf break, the Irminger seawater core is displaced onshore while the stratification weakens with the increase in isopycnal slope. The change in stratification is partially due to the onshore shift of the "classical" Labrador Current, baroclinic instability, and possibly slantwise convection.
\end{abstract}

\section{Introduction}

The Labrador Sea boundary circulation is made of three main components: the West Greenland Current, the Labrador Current, and the North Atlantic Current. The West Greenland Current flows northward along the western coast of Greenland (Fig. 1). It carries fresh and cold water on the shelf and warmer and saltier Irminger seawater at 200-500-m depth above the continental slope (Fig. 2). Similarly, the Labrador Current carries fresh and cold Arctic water onto the shelf and Irminger seawater, which has transited the perimeter of the basin above the upper continental slope. The circulation above the continental slopes of the Labrador Basin is composed of a more baroclinic component flowing between the 1000- and 2000-m isobaths, moving from east to north to west (the West Greenland Current, the West Greenland Current extension, and the Labrador Current), and a more barotropic component centered approximately above the 2500-m isobath named uniformly for the entire basin, the deep Labrador Current (Lazier and Wright 1993; Cuny et al. 2002).

Corresponding author address: Jérôme Cuny, Institut d'Astronomie et de Geophysique Georges Lemaître, 2 Chemin du Cyclotron, Louvain-La-Neuve, 1348 Louvain-La-Neuve, Belgium. E-mail: cuny@astr.ucl.ac.be
The 3000-m isobath is often considered as the offshore limit of the deep Labrador Current. The deeper circulation is made of the deep western boundary current carrying Denmark Strait Overflow Water (DSOW) at the bottom and Iceland-Faeroe Strait Overflow Water (ISOW) above it.

The Labrador Sea plays an essential role in the thermohaline circulation as it is one of the rare locations where Atlantic Intermediate Water forms. Every winter, cold outbreaks from the Canadian Arctic create very large air-sea heat fluxes over the ice-free waters of the Labrador Sea. This triggers instability in the water column, and thus vertical mixing within short-lived plumes. Labrador Sea Water (LSW) is formed through this convection process. The convection depth and the area affected by convection vary interannually (Lazier et al. 2002) because of the variability in forcing and preconditioning of the water column. The preconditioning, that is, the state of the stratification at the end of the autumn season, is a result of the interaction between the interior and the boundary currents through summer-autumn (Cuny et al. 2002; Lilly et al. 1999; Lilly 2003). These factors affect the formation rate of LSW which ranges from $2-3 \mathrm{~Sv}\left(\mathrm{~Sv} \equiv 10^{6} \mathrm{~m}^{3} \mathrm{~s}^{-1}\right)$ in years of weak forcing to $12 \mathrm{~Sv}$ in years of intense atmospheric forcing (Rhein et al. 2002; Smethie and Fine 2001). The Labrador Sea Water leaves the Labrador Sea 
(a)

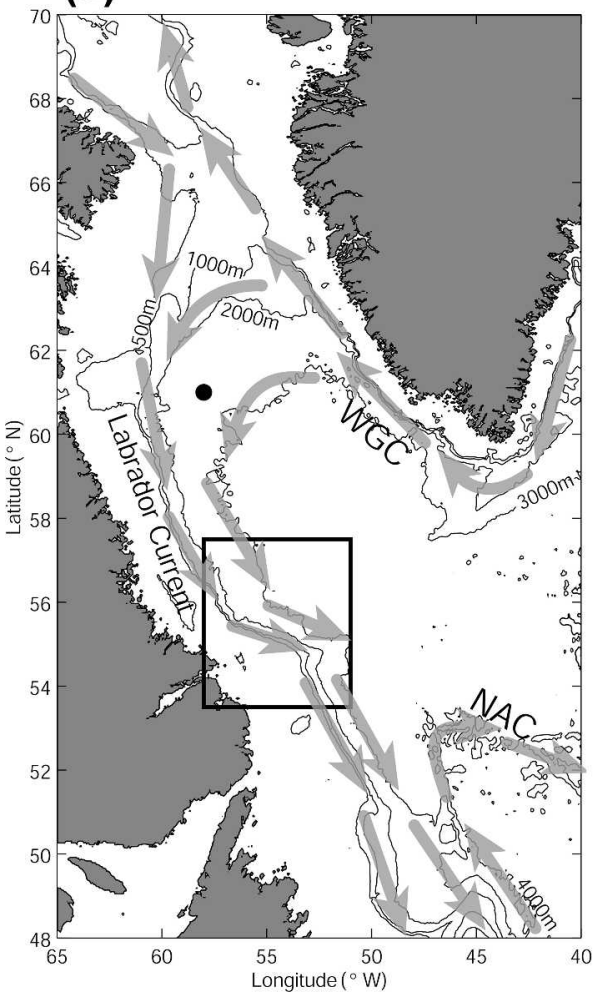

(b)

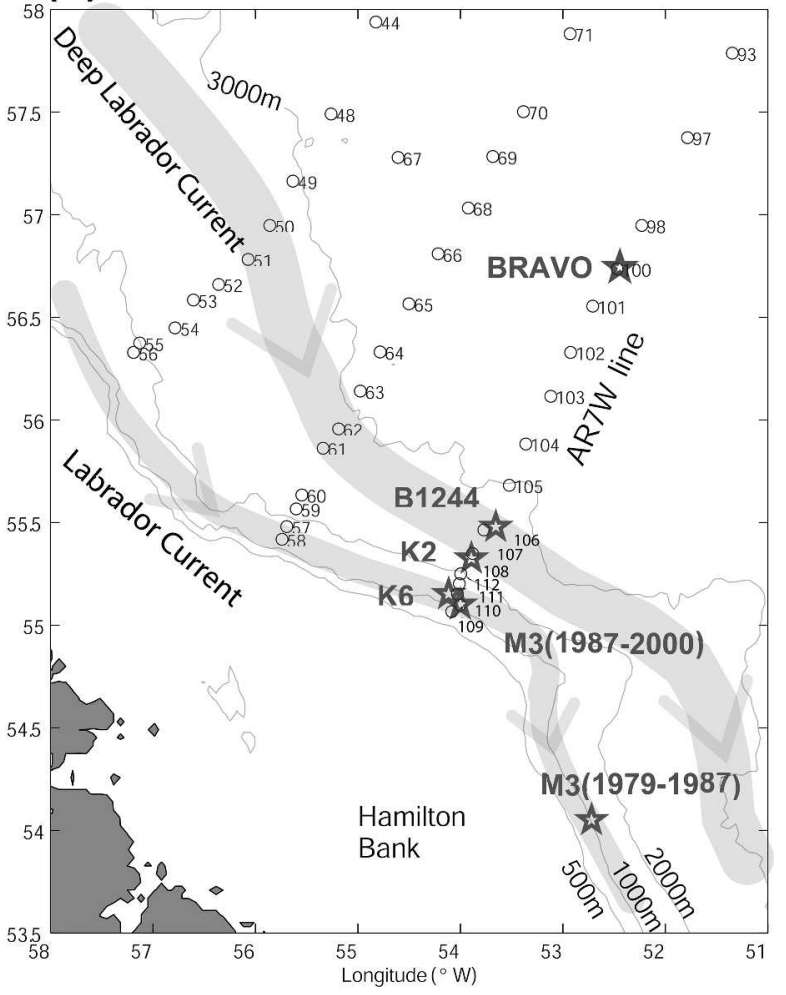

FIG. 1. Presentation of the data used in this study. (a) The general circulation of the Labrador Sea (WGC: West Greenland Current; NAC: North Atlantic Current). The black dot in the inset indicates the location of the northernmost station of the NW-SE hydrographic section occupied in Nov 1996, used for the Lagrangian model described in section 4c. The rectangle shows the limits of the region presented in (b). (b) The locations of the moorings M3/K6, K2, B1244, and Bravo are marked with stars. The mooring M3 was located south of Hamilton Bank from 1979 to 1987 and north of it from 1987 to present. In 1987/88, mooring M8 was located very close to where K2 was in 1996/97. Some of the stations occupied during the Feb-Mar 1997 R/V Knorr cruise are also shown.

along three main paths: toward the Irminger Basin, the Iceland Basin through the Charlie-Gibbs Fracture Zone, and southward with the DWBC (Lavender et al. 2000).

There are three main characteristics common to most deep convection sites (e.g., Greenland Sea, Golfe du Lion, and Labrador Sea): a weak stratification beneath the mixed layer, a cyclonic gyre that traps water within and brings deep water closer to the surface by doming of the isopycnals, and a strong atmospheric forcing to overcome the surface stratification (Marshall and Schott 1999). These conditions observed at most convection sites suggest that deep convection is unlikely to take place along the fast-flowing Labrador Sea boundary currents. For instance, the deep Labrador Current flows at $15 \mathrm{~cm} \mathrm{~s}^{-1}$ on average and the combination of warm Irminger seawater (ISW) capped by fresh Arctic Water makes the top $1000 \mathrm{~m}$ of the water column more buoyant by $22 \mathrm{~m}^{2} \mathrm{~s}^{-2}$ than a water column from the interior Labrador Sea, hence constituting a strong barrier to vertical overturning (Fig. 2). However, some observations of the homogenization of the water column in the Labrador Current have been made with hydrographic data collected during the convection period
(Pickart et al. 2002). Pickart et al. (2002) found that the product of convection above the lower Labrador slope would be hardly differentiable from the interior product once advected far away from the Labrador Sea. In addition, Pickart et al. (1997) suggested that the Labrador shelf break was the location of the formation of Upper Labrador Sea Water, a water mass observed downstream close to Flemish Cap with densities around 27.68-27.72 $\sigma_{0}$.

There are a few reasons that call for a distinction between the convection taking place at the boundary and in the interior Labrador Sea. Kawase (1987) showed with his model experiment of abyssal circulation spinup that any changes in the intensity of the sinking are first transmitted equatorward by Kelvin waves. If convection took place above the topographic boundary, the generation of a topographic wave would occur earlier than if convection took place only in the open ocean. Hence, the signal associated with variability in the intensity of convection above the continental slope would be transmitted earlier to the lower latitudes than the signal associated with the interior convection. Spall and Pickart (2001) also pointed out the 


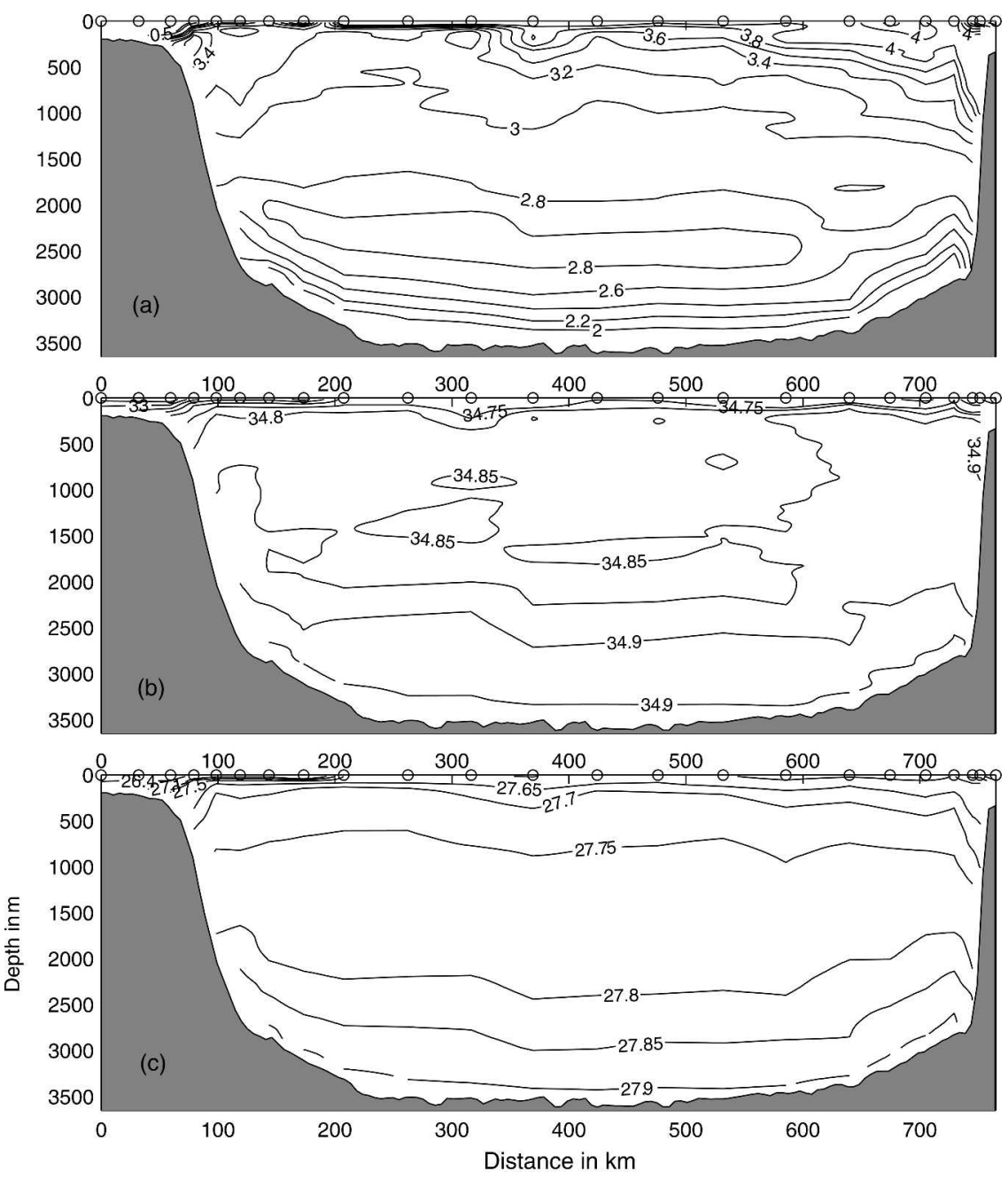

FIG. 2. (a) Potential temperature $\left({ }^{\circ} \mathrm{C}\right)$, (b) salinity, and (c) potential density $\sigma_{0}\left(\mathrm{~kg} \mathrm{~m}^{-3}\right)$ contours from the May 1997 AR7W hydrographic section.

importance of the steep boundaries at northern latitudes for the meridional overturning circulation. They showed that downwelling, as opposed to simple watermass transformation, does not take place in the region of deepest mixed layers but rather above the steep boundary nearby where less intense vertical mixing takes place. Most climate models overemphasize the role of the Labrador Sea convection in the sinking branch of the meridional overturning circulation, such that it is necessary that the interior and boundary current annual cycle be well described from observations for any meaningful comparison and possible improvement of the models. Last, one can assume that any changes in the properties of the waters formed by convection in the boundary current at high latitudes would be advected southward much faster, thus observed earlier at low latitudes (Molinari et al. 1998) than any change taking place in the interior convection region (Spall and Pickart 2001).
Straneo et al. (2002) modeled from a 2D perspective the winter change in stratification above the Labrador slope using a realistic initial condition and realistic forcing from the 1996/97 winter. They were able to point out some aspects of the vertical overturning taking place in the boundary current, such as the role of horizontal stratification, in favoring slantwise convection-that is, mixing along absolute momentum lines, and the role of Ekman fluxes in carrying denser offshore waters above the Labrador slope, thus adding to the surface buoyancy forcing. Legg et al. (1998) have pointed out, in a 3D numerical experiment with a uniform forcing above an eddy structure, the key role played by a secondary circulation set up by convection that strengthens the frontal region and thus generates baroclinic instability. The eddy fluxes due to the instability restratify the water column without shutting down the convection process. Hence, baroclinic instability sustains a mixing, which takes place now along more 


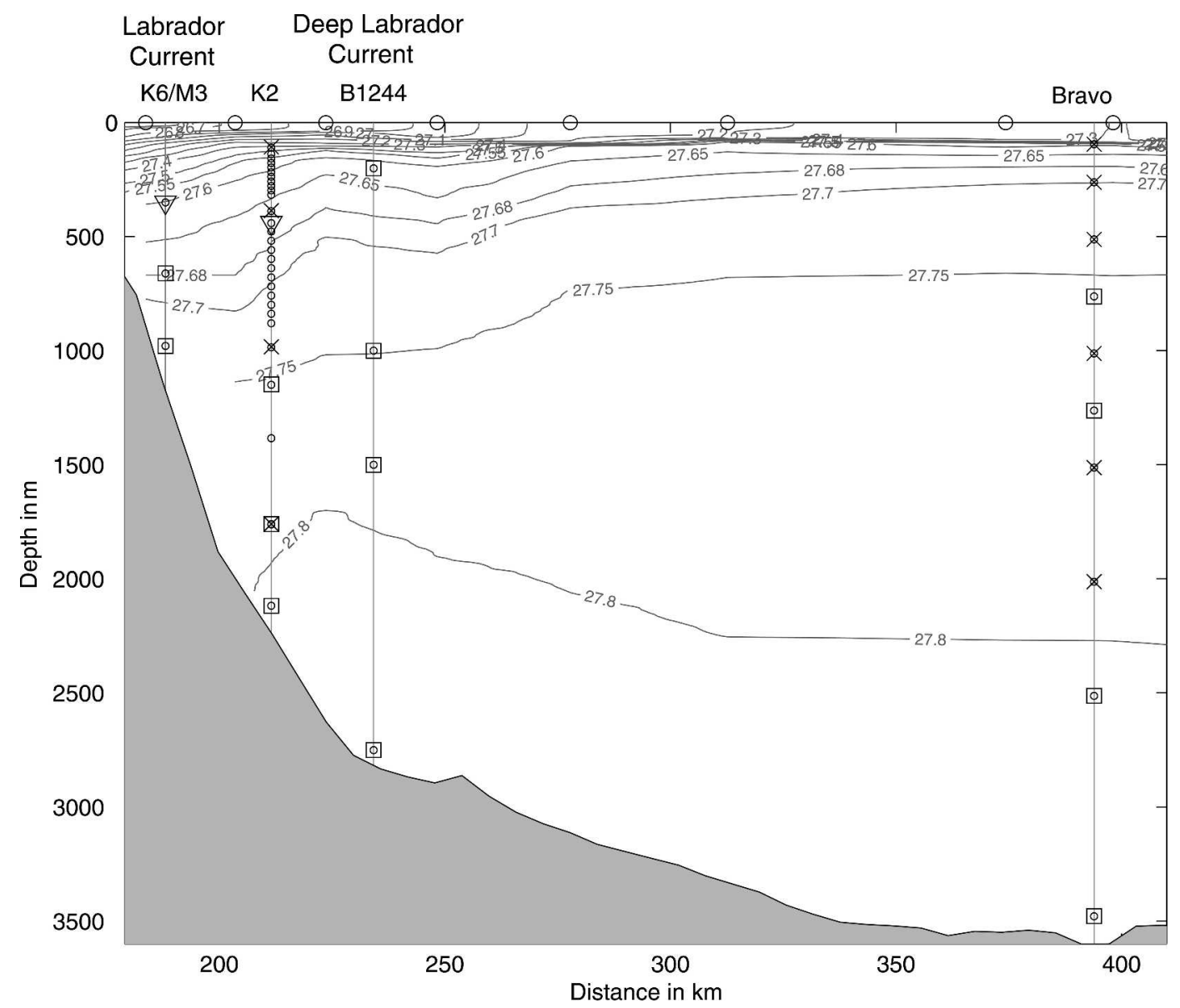

FIG. 3. Instrument locations on the different moorings used in this study with the potential density $\sigma_{0}\left(\mathrm{~kg} \mathrm{~m}^{-3}\right)$ contours from the Oct 1996 AR7W hydrographic section in the background. Small circles indicate temperature recorders. Squares indicate current meters. Upward triangles indicate upward-looking ADCP. Crosses indicate conductivity sensors, combined here with temperature sensors on Seacat instruments. The location of K6/M3 corresponds to the core of the shelfbreak Labrador Current. The location of B1244 corresponds to the core of the deep Labrador Current.

slanted paths in an environment with non-nelglectable stratification.

Here, we use data collected by several moorings located above the Labrador continental slope along the AR7W line (Figs. 1 and 3) to look closely at the processes taking place during the winter 1996/97 in the Labrador Current. The potential temperature record from several moorings across the Labrador slope (Fig. 4) bears a lot of resemblances to the record from the Bravo mooring located in the interior Labrador Sea. They all show a rapid cooling period, followed by a short period when several instruments show uniform water properties, and finally a warming period that begins at the end of spring. The Bravo mooring record is representative of the convective processes taking place in the interior Labrador Sea (Lilly et al. 1999); hence, one wonders to what extent the processes taking place above the Labrador slope in winter are similar to the interior ones. The moorings combined with hydro- graphic data allowed us to differentiate the processes taking place in the more barotropic "deep" Labrador Current (section 4) and the more baroclinic "classical" Labrador Current above the shelf break (section 5).

From this data, we find that a close study of the onset of convection in the deep Labrador Current discards the possibility that the denser waters observed are simply advected from offshore. We find discrepancies between the water column heat loss and the atmospheric heat fluxes in the deep Labrador Current, whether we consider an Eulerian or Lagrangian 1D approach over one winter. We attribute these discrepancies to lateral eddy fluxes and the preconditioning effect by eddies of low potential vorticity water advected from offshore. At the shelf break, the stratification weakens throughout the winter but remains significant. The weakening of the vertical stratification is mostly due to a steepening of the isopycnals, which hints toward dynamical change in the shelfbreak Labrador Current, and the 

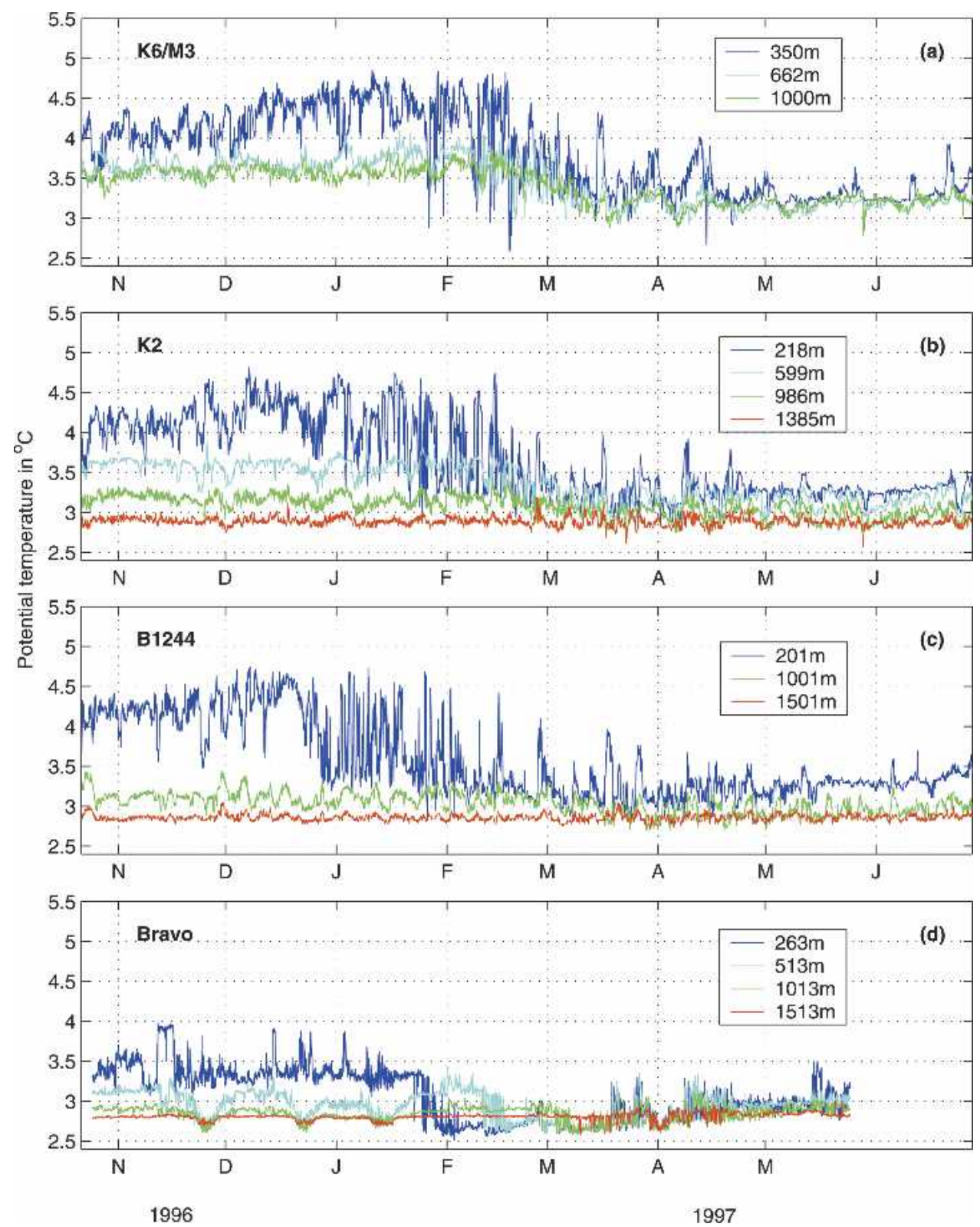

FIG. 4. Potential temperature $\left({ }^{\circ} \mathrm{C}\right)$ from several moorings located along the May 1997 AR7W hydrographic line during the period Oct 1996-Jun 1998 (see Fig. 1 for locations): (a) K6/M3, (b) K2, (c) B1244, and (d) Bravo. Monthly ticks correspond to the first day of each month.

possible effect of baroclinic instability and slantwise convection. However, we were not able to find direct evidence of slantwise convection. Close to the shelf break, one has to consider other forcings in addition to the atmospheric forcing, such as the Ekman transport of denser offshore water and the cooling by sea ice.

The structure of this manuscript is as follows. The velocity record from a mooring placed within the deep Labrador Current is described in section 3. The description of the winter processes is, in section 4 , for the deep Labrador Current and, in section 5, for the shelfbreak area. The data are described in section 2, and results are summarized in section 6 .

\section{Data description}

\section{a. Moorings}

The mooring locations are shown in Fig. 1 and general information is presented in Table 1. Labrador Sea interior convection is monitored with a mooring often called Bravo because of its proximity to the location of 
TABLE 1. Mooring location and instruments. In addition, K2 carried 23 thermistors between 111 and $1385 \mathrm{~m}$. They were spaced every $20 \mathrm{~m}$ between 138 and $318 \mathrm{~m}$ and every $40 \mathrm{~m}$ from 479 to $839 \mathrm{~m}$. The remaining ones were at 111, 441, 881, and 1385 m.

\begin{tabular}{|c|c|c|c|c|c|c|}
\hline Mooring & Location & Period & $\mathrm{RCM}$ & $\mathrm{ACM}$ & Seacat & $\mathrm{ADCP}$ \\
\hline Bravo (UW/BIO) & $56^{\circ} 45.2^{\prime \circ} \mathrm{N}, 52^{\circ} 27.5^{\prime \circ} \mathrm{W}$ & May 1995-Oct 1996 & $\begin{array}{r}763 \\
1263 \\
2513 \\
3479\end{array}$ & & $\begin{array}{r}96 \\
263 \\
513 \\
1013 \\
153 \\
2013\end{array}$ & \\
\hline B1244 (UW/BIO) & $55^{\circ} 28.72^{\prime \circ} \mathrm{N}, 53^{\circ} 39.3^{\circ}{ }^{\circ} \mathrm{W}$ & Oct 1996-Jun 1998 & $\begin{array}{r}200 \\
1000 \\
1500 \\
2750\end{array}$ & & & \\
\hline M3(UW/BIO) & $54^{\circ} 3.15^{\prime \circ} \mathrm{N}, 52^{\circ} 43.7^{\circ} \mathrm{W}$ & Aug 1979-Jun 1987 & 1000 & & & \\
\hline M3(UW/BIO) & $55^{\circ} 5.43^{\prime \circ} \mathrm{N}, 54^{\circ} 1.91^{\prime \circ} \mathrm{W}$ & Jun 1987-May 2000 & 1000 & & & \\
\hline $\mathrm{K} 2$ (lfm) & $55^{\circ} 19.5^{\prime \circ} \mathrm{N}, 53^{\circ} 53.6^{\prime \circ} \mathrm{W}$ & Aug 1996-Jul 1997 & & $\begin{array}{l}1148 \\
1761 \\
2118\end{array}$ & $\begin{array}{r}108 \\
387 \\
984 \\
1760\end{array}$ & $440 \mathrm{U}$ \\
\hline $\mathrm{K} 6(\mathrm{lfm})$ & $55^{\circ} 9.1^{\prime \circ} \mathrm{N}, 54^{\circ} 6.9^{\prime \circ} \mathrm{W}$ & Aug 1996-Jul 1997 & 662 & & & $350 \mathrm{U}$ \\
\hline
\end{tabular}

the former Ocean Weather Station Bravo (Lilly et al. 1999). A mooring has been deployed several times at this location since May 1994. We principally use the data collected in 1996/97. The mooring B1244 located above the 2800-m isobath was near the core of the deep boundary current. Statistics for this mooring are presented in Table 2. The moorings $\mathrm{K} 2$ and $\mathrm{K} 6$ were deployed by IfM Kiel above the 2400- and 1000-m isobaths. Mooring M3 has been regularly maintained by Bedford Institute of Oceanography since 1978 (Rhines and Lazier 1995). The mooring that had been recording both temperature and velocity at 1000-m depth was first placed above the 1000-m isobath south of Hamilton Bank before being moved north of Hamilton Bank along the AR7W line during 1987.

\section{b. Hydrographic data}

Every spring since 1990, the Bedford Institute of Oceanography has been carrying out hydrographic sections between Hamilton Bank, Labrador, and Cape Desolation, Greenland (WOCE line AR7W). In 1996 and 1997, additional hydrographic sections were made for the Labrador Sea Deep Convection Experiment. In October 1996, a hydrographic section oriented in the northwest-southeast direction was carried out in addition to one along the AR7W line (Cuny et al. 2002). In
February-March 1997, the R/V Knorr collected an extensive number of hydrographic casts covering the western part of the Labrador Sea where the deepest convection was expected to occur (Pickart et al. 2002).

\section{Velocity record in the "deep" Labrador Current}

The mooring B1244 located above the 2800-m isobath monitors the evolution of the "deep" Labrador Current. The across-isobath speeds are a tenth of the along-isobath speeds (Table 2). The velocity record shows a maximum in along-isobath velocity in MayJune 1997 and a minimum around November 1997 (Fig. 5a). However, the standard deviations around the monthly means are too large to deduce a significant seasonal cycle from the 21-month record. Similarly, the monthly mean across-isobath velocity record does not show a clear seasonal signal (Fig. 5b). Lazier and Wright (1993) observed a maximum along-isobath speed around February and a minimum around April from mooring M8 located at the 2500-m isobath along the AR7W line in $1987 / 88$. If we demean and detrend the B1244 velocity record, we observe such a seasonal signal in 1998 but not in 1997 . Using this modified record, we also find that the annual harmonic represent less than $10 \%$ of the variance in most cases (not

TABLE 2. Mooring B1244 statistics, mean \pm std dev.

\begin{tabular}{|c|c|c|c|c|c|c|}
\hline $\begin{array}{l}\text { Depth } \\
(\mathrm{m})\end{array}$ & $\begin{array}{l}\text { Zonal speed } \\
\qquad\left(\mathrm{cm} \mathrm{s}^{-1}\right)\end{array}$ & $\begin{array}{l}\text { Meridional speed } \\
\quad\left(\mathrm{cm} \mathrm{s}^{-1}\right)\end{array}$ & $\begin{array}{l}\text { Speed } \\
\left(\mathrm{cm} \mathrm{s}^{-1}\right)\end{array}$ & $\begin{array}{c}\text { Temperature } \\
\left({ }^{\circ} \mathrm{C}\right)\end{array}$ & $\begin{array}{c}\text { Along-isobath }\left(115^{\circ} \mathrm{T}\right) \\
\text { speed }\left(\mathrm{cm} \mathrm{s}^{-1}\right)\end{array}$ & $\begin{array}{l}\text { Across-isobath } \\
\text { speed }\left(\mathrm{cm} \mathrm{s}^{-1}\right)\end{array}$ \\
\hline 200 & $14.1 \pm 10.9$ & $8.9 \pm 11.2$ & $20.6 \pm 10$ & $3.6 \pm 0.4$ & $16.6 \pm 11.6$ & $2 \pm 11$ \\
\hline 1000 & $12.3 \pm 8.8$ & $7.5 \pm 8.7$ & $17.2 \pm 8$ & $3 \pm 0.1$ & $14.3 \pm 9$ & $1.5 \pm 8.5$ \\
\hline 1500 & $12.9 \pm 8$ & $5.2 \pm 7.6$ & $16.3 \pm 7.1$ & $2.8 \pm 0.05$ & $13.9 \pm 8.2$ & $0.7 \pm 7.4$ \\
\hline 2750 & $20.7 \pm 7.5$ & $11.8 \pm 5.7$ & $24.4 \pm 8$ & $1.7 \pm 0.1$ & $23.8 \pm 8.2$ & $1.9 \pm 4.7$ \\
\hline
\end{tabular}




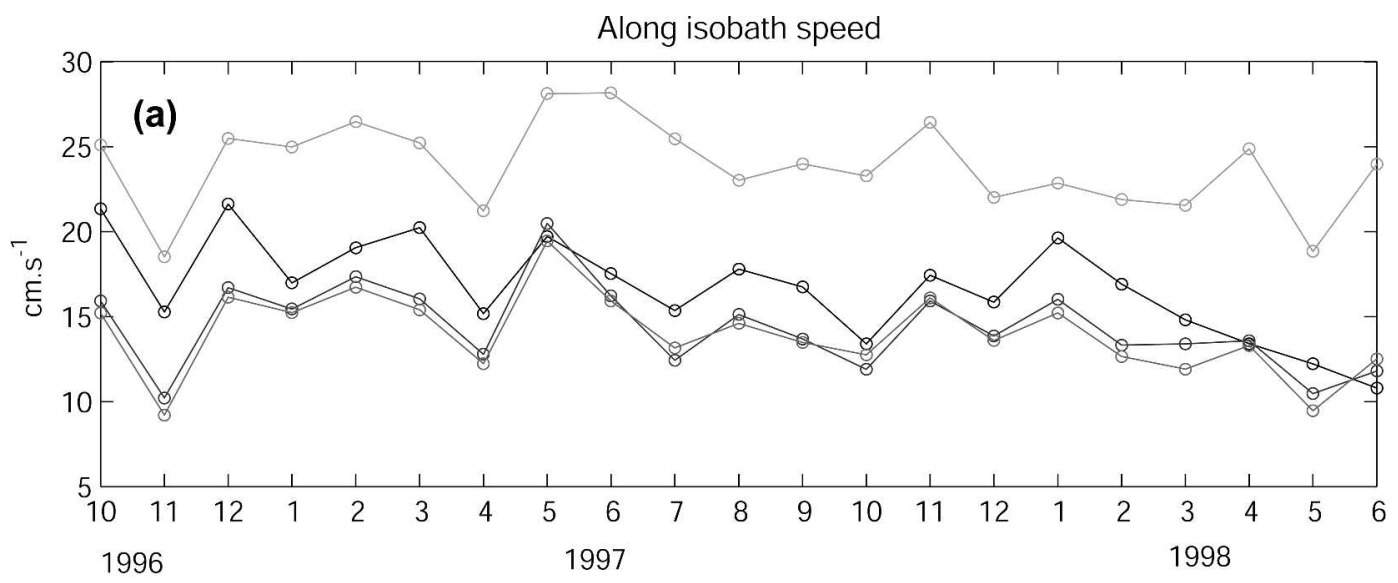

Across isobath speed

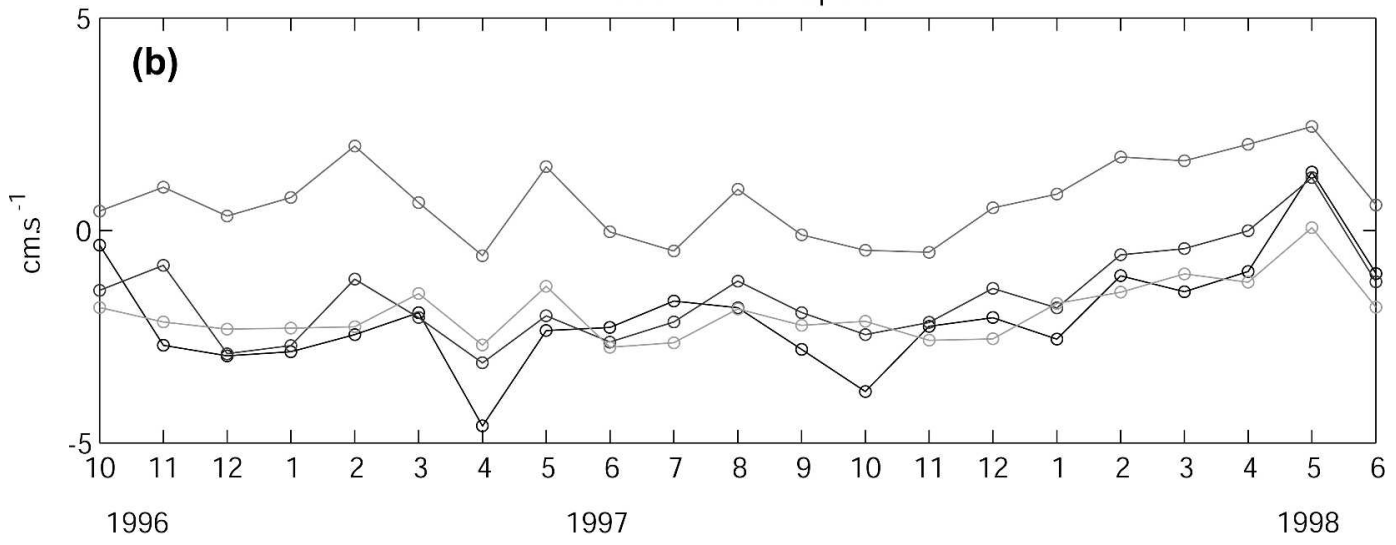

FIG. 5. Monthly mean (a) along-isobath speed $\left(\mathrm{cm} \mathrm{s}^{-1}\right)$ and (b) across-isobath speed $\left(\mathrm{cm} \mathrm{s}^{-1}\right)$ at the four instruments at mooring B1244. Negative across-isobath speed is toward offshore. Instruments were at 200, 1000, 1500 , and $2750 \mathrm{~m}$. The darker line is for the shallowest instrument. The deepest instrument shows the largest along-isobath speed. We did not draw the error for each monthly estimates for clarity purposes.

shown). We note that the bottom flow speed is faster at B1244 than was reported at M8 (Lazier and Wright $1993)$, suggesting that the core of the DWBC is closer to the $2800-\mathrm{m}$ isobath.

Combining the mooring data with hydrographic data collected from October 1996 to June 1998, we computed absolute velocity profiles for the water column close to the mooring B1244 (Figs. 6a-e). The 1500-m instrument speed averaged over the four days surrounding the time of the CTD station is added to the geostrophic velocity deduced from the CTD section with a level of no motion assumed at $1500 \mathrm{~m}$. This shows that the vertical shear over the top $1500 \mathrm{~m}$ is always weak in this part of the current $\left(4.2 \times 10^{-5} \pm 6.5\right.$ $\times 10^{-5} \mathrm{~s}^{-1}$ in October 1996 and $4 \times 10^{-5} \pm 1.9 \times 10^{-5}$ $\mathrm{s}^{-1}$ in February 1997) and that the moored instruments capture well the vertical current structure. In May 1997 the speed is amazingly uniform from the surface down to $1600 \mathrm{~m}$. The minimum surface speed is generally observed in the winter profiles. The June 1998 profile shows very weak speed at the surface in comparison with the autumn 1996 and spring 1997 profiles. How- ever, we found that the June 1998 profile was more dependent than the other profiles on the number of days over which we averaged the mooring velocity data. Again for the period 1996-98, we do not observe the seasonal signal for the deep Labrador Current suggested by Lazier and Wright (1993). It is unclear if the weaker speeds observed in the winter are part of the seasonal cycle or are simply due to an across-isobath shift of the current core.

At mooring B1244, the monthly mean variance is minimum in November, then grows through the winter to reach a maximum in March-April in both the along and across-isobath speed records (Fig. 7). This agrees well with the Ocean Topography Experiment (TOPEX) observations, which show a maximum in eddy kinetic energy $\left(350 \mathrm{~cm}^{2} \mathrm{~s}^{-2}\right.$ on average over 1994 2000) in the Labrador Current in March-April (J. Lilly 2003, personal communication) but not with the model results of Eden and Böning (2002) who found a maximum in January. The current meandering associated with the peak in speed variance at the end of winter matches with the concept of large-scale ocean convec- 

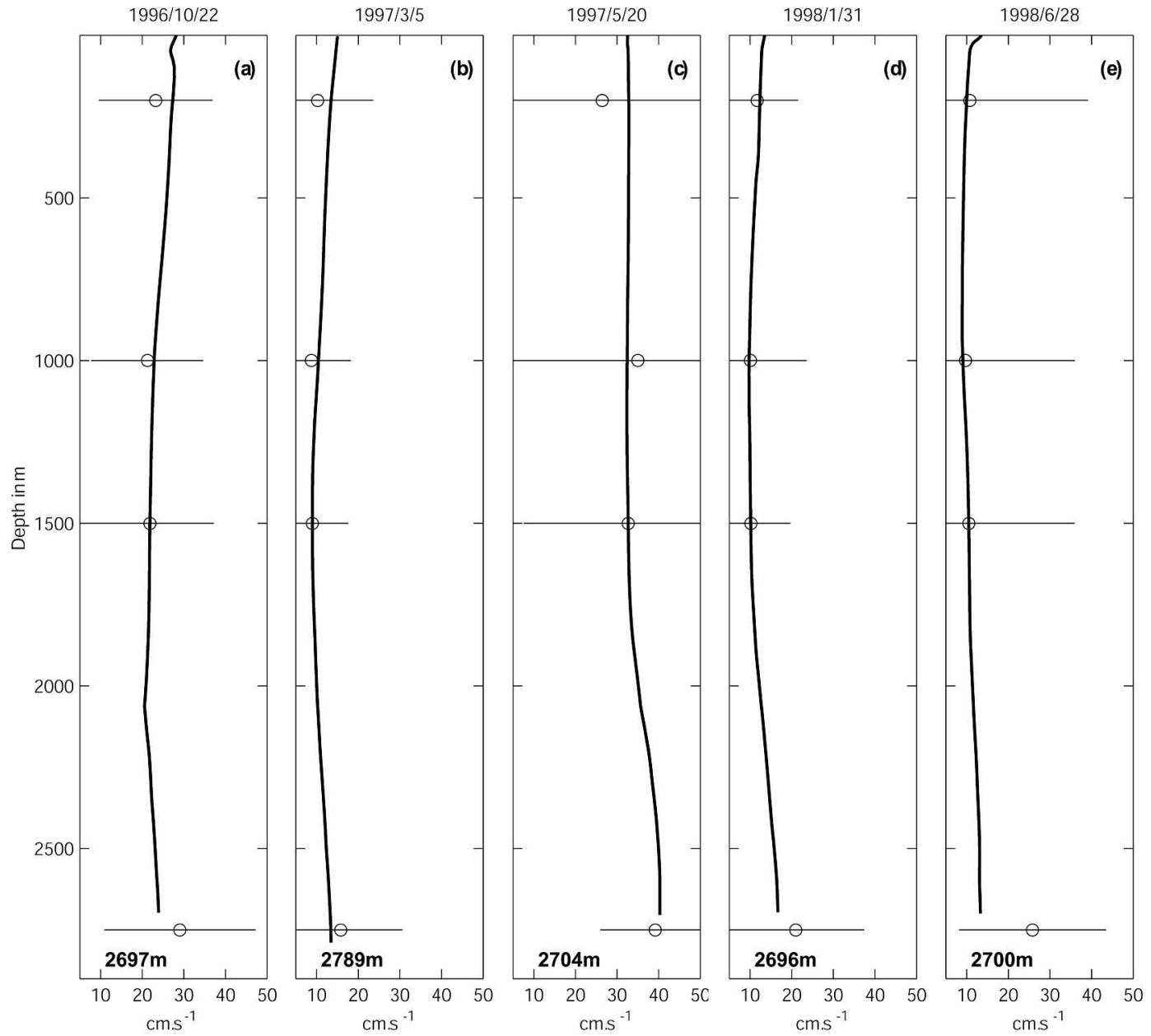

FIG. 6. Absolute speed $\left(\mathrm{cm} \mathrm{s}^{-1}\right)$ profile across the AR7W line at the stations closest to mooring B1244 in (a) Oct 1996, (b) Mar 1997, (c) May 1997, (d) Jan 1998, and (e) Jun 1998. The bottom depth at the station used for each profile is given in the lower-left corner of each subplot. The circles indicate the mean speed measured by the instruments at B1244 for the 4 days surrounding the time of the station. The error bars on the mooring estimates represent the $95 \%$ confidence interval on the mean deduced from the 4 days of data. The correlation time scale from the mooring velocity data is around 1.2 days, which makes for very few degrees of freedom over a 4-day period. This explains the large error bars on all the mean estimates.

tion in which the rim current of the convective region reaches a peak of instability at the end of the convection period (Marshall and Schott 1999).

\section{Convection above the lower Labrador slope}

Moorings above the lower Labrador slope recorded vertically uniform temperatures at several instruments during winter (Fig. 4), but it is necessary to discard the possibility that the colder waters are not simply lateral intrusions of offshore water. For this purpose, we used the data collected by the Seacat instruments at mooring $\mathrm{K} 2$ located above the 2400-m isobath. These were the only instruments providing both temperature and salinity information above the Labrador slope during the 1996/97 winter. Density at $108 \mathrm{~m}$ decreased irregularly until mid-December 1996 while the temperature and salinity decreased irregularly since mid-October (Fig. $8 \mathrm{a})$, with the salinity having a larger influence. Then from mid-December 1996 to mid-January 1997, the density increased by $0.2 \mathrm{~kg} \mathrm{~m}^{-3}$ at the top instrument. During this period, the density at the four instruments $(108,387,984,1760 \mathrm{~m})$ showed bumps of denser water, presumably coming from offshore, which lasted 7-10 days. We note that, after the passage of each of these bumps, the density at the three bottom instruments returned to their initial value. However, the density at the top instrument kept on increasing. The potential temperature record (Fig. 8b) showed similar bumps as the density record at 387 and $984 \mathrm{~m}$ but the top instrument differed by an increase in the amplitude of the fluctuations with periods on the order of days starting at the end of December. The "corrected" National Centers for Environmental Prediction (NCEP) heat fluxes 
Along isobath speed variance

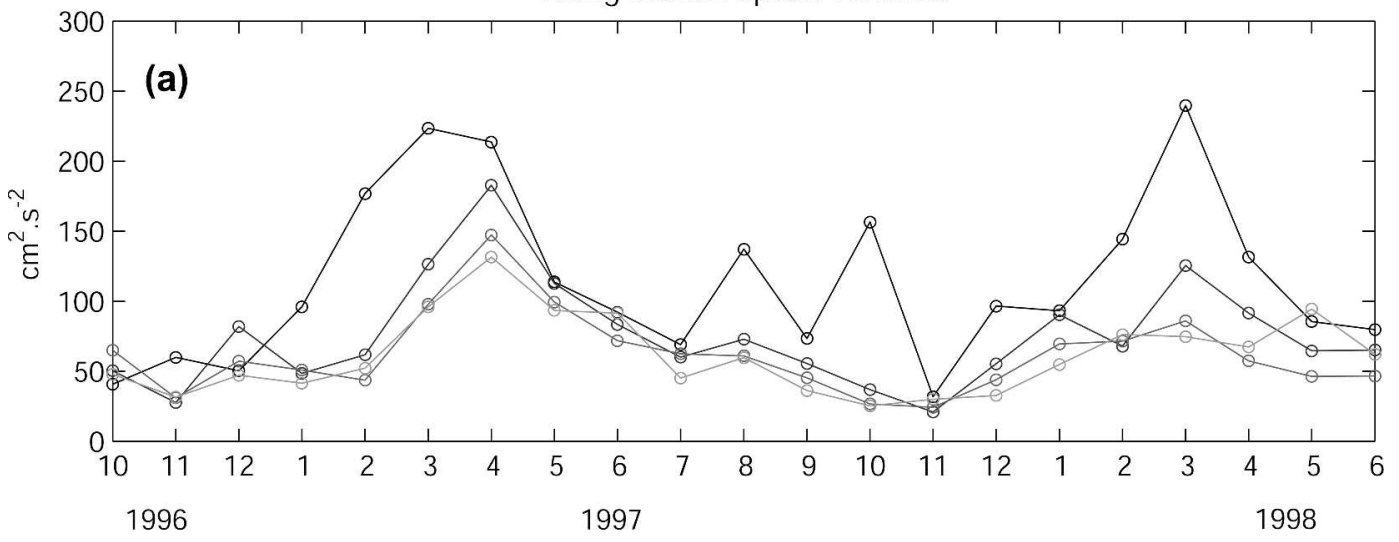

Across isobath speed variance

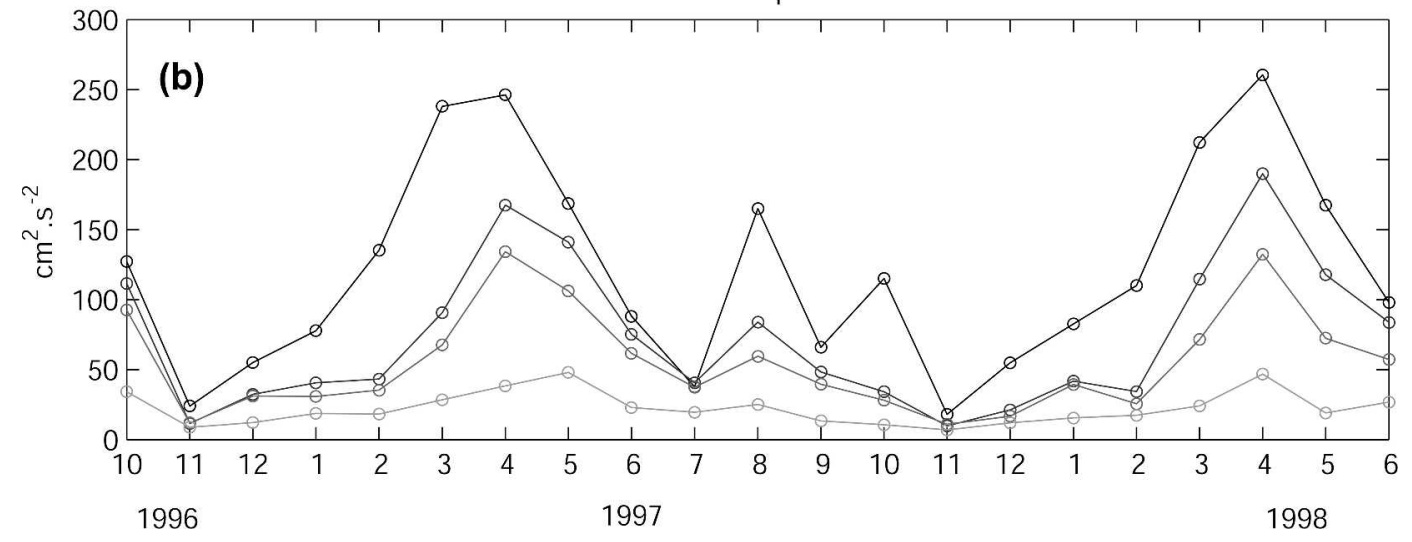

FIG. 7. Monthly mean (a) along-isobath speed variance $\left(\mathrm{cm}^{2} \mathrm{~s}^{-2}\right)$ and (b) across-isobath speed variance $\left(\mathrm{cm}^{2} \mathrm{~s}^{-2}\right)$ at the four instruments at mooring B1244. Instruments were at 200,1000,1500, and $2750 \mathrm{~m}$. The darker line is for the shallowest instrument. The deepest instrument shows the weakest variance.

above the Labrador slope (Renfrew et al. 2002) presented a period of high values during the last 10 days of 1996 (Fig. 8c), including a peak at $450 \mathrm{~W} \mathrm{~m}^{-2}$, corresponding to the passage of a storm. This surface forcing event might be responsible for the vertical mixing reaching $100 \mathrm{~m}$ deep and generating high-frequency fluctuations.

\section{a. Phases of convection}

We used the mooring B1244 to study the different phases of convection in the temperature record. The potential temperature record from B1244 at 200 and $1000 \mathrm{~m}$ shows a regular annual oscillation over the 21month long record (Fig. 9). At the 200-m instrument, the temperature is maximum in mid-December 1996 and 1997 and minimum at the end of March 1997 and 1998. We observe a similar oscillation at the $1000-\mathrm{m}$ instrument with maxima observed at the end of February $1997\left(3.1^{\circ} \mathrm{C}\right)$ and at the beginning of March 1998 $\left(3.2^{\circ} \mathrm{C}\right)$ and minima in mid-April $1997\left(2.9^{\circ} \mathrm{C}\right)$ and March $1998\left(3.08^{\circ} \mathrm{C}\right)$. At the $1500-\mathrm{m}$ instrument, the potential temperature varies between $2.85^{\circ}$ and $2.95^{\circ} \mathrm{C}$, with slightly more variability at the end of the convection period in March-April. The temperature at $2750 \mathrm{~m}$ oscillated greatly between $1.5^{\circ}$ and $2^{\circ} \mathrm{C}$ throughout the entire record.

If we take a closer look at the potential temperature record, we notice that the cooling goes through several phases during both winters. There was first an extremely rapid cooling phase, followed by a more irregular period with alternating warm and cold peaks, and finally a short period with a more constant temperature and a few intermittent spikes. The initial intense cooling takes place in two steps (Fig. 10). The first cooling of $0.4^{\circ} \mathrm{C}$ takes place from day 355 until day 358 of 1996 . The cooling is observed at the adjacent 200-m-deep instruments of K2 and B1244 but not at shallower instrument at K2 (Fig. 10), suggesting that it is due to mixing with a significant lateral component. Then, warmer water goes through B1244 at $200 \mathrm{~m}$ before the second intense cooling takes place from day 361 to 1 January 1997. This second cooling step is observed at the 200-m instrument of B1244, at the 111-m instrument at K2, but not at the 200-m instrument of K2 where temperature actually increased back to its mid-December range. The 

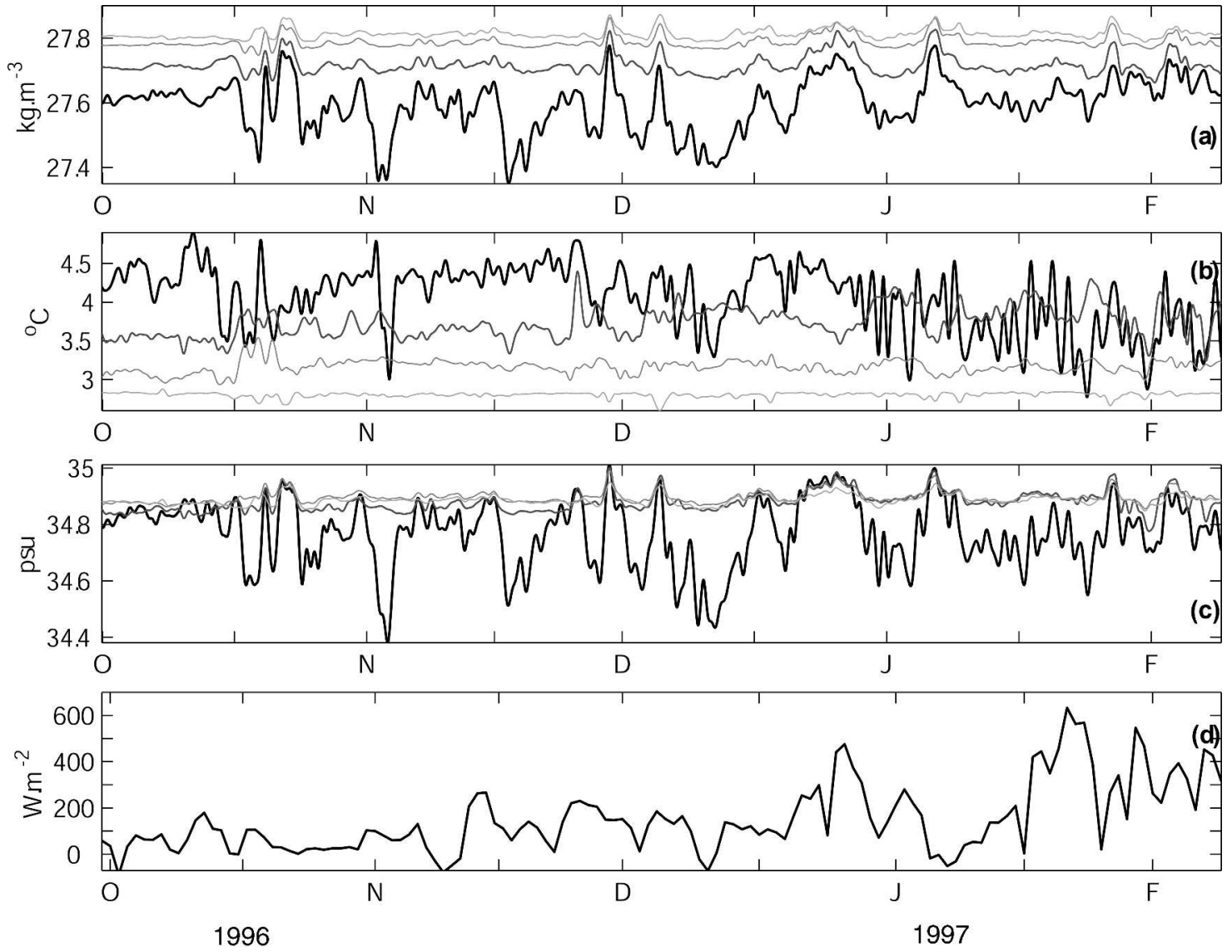

Fig. 8. (a) Potential density $\sigma_{0}\left(\mathrm{~kg} \mathrm{~m}^{-3}\right)$, (b) potential temperature $\left({ }^{\circ} \mathrm{C}\right)$ records, and $(\mathrm{c})$ salinity records from the 108-, 387-, 984-, and 1760-m instruments at K2 at the end of autumn-beginning of winter. The time series are low-pass filtered with a cutoff at $27 \mathrm{~h}$. The darkest line is for the shallowest instrument. (d) Atmospheric heat fluxes from corrected NCEP heat fluxes (Renfrew et al. 2002). Monthly ticks correspond to the first day of each month.

high-frequency fluctuations at $111 \mathrm{~m}$ at $\mathrm{K} 2$ suggest that active mixing with a more dominant vertical component is taking place. This leads us to think that the second cooling step observed at B1244 is related to a deepening of the surface mixed layer. The stratification being stronger closer to the shelf break, vertical mixing will take place later at $200 \mathrm{~m}$ at K2 than at B1244.

The second phase, which shows an irregular cooling, corresponded to the active vertical mixing period. The warm spikes observed mostly during January 1997 reach temperatures close to the maximum temperature of December 1996 before the beginning of cooling. These cannot be due to a tilting of the instruments because the autumn 1996 section revealed that the ISW core was at 60-m depth above the lower Labrador slope (Pickart et al. 2002, their Fig. 8a). Moreover, the pressure sensor at the 200-m instrument showed only weak variability during that period with maximum changes of 15 dbar. The warm spikes are attributed to the inhomogeneity of the mixed layer along the current.

We suspect that the spatial inhomogeneity in mixing is due to spatial inhomogeneity in atmospheric forcing, the current meandering, as well as spatial variations in the initial vertical stratification-that is, "preconditioning" (Straneo and Kawase 1999). Similarly, Pickart et al. (2002) have reported a great deal of spatial inhomogeneity of convective mixing in the interior Labrador Sea. We cannot discard the possibility that some of the cold water observed corresponds to plumes. The lack of vertical velocity measurements at B1244 prevents from distinguishing plumes from passages of convected water patches. However, the mean flow speed being about 15 $\mathrm{cm} \mathrm{s}^{-1}$, a plume with 1-km scale would take only $2 \mathrm{~h}$ to pass through mooring B1244, while most of the colder water passages in January lasted at least $8 \mathrm{~h}$. We also did not find any specific rotation associated with these cold features.

If we separately plot the high-frequency fluctuations from the K2 instruments, we observe a sudden increase in magnitude that propagates deeper as the mixed layer bottom passes through the instruments (Figs. 11a-c). The periods emphasized on the figure suggest an approximate lag of 28 days between 108 and $384 \mathrm{~m}$ and 29 days between 384 and $987 \mathrm{~m}$ for the onset of the in- 


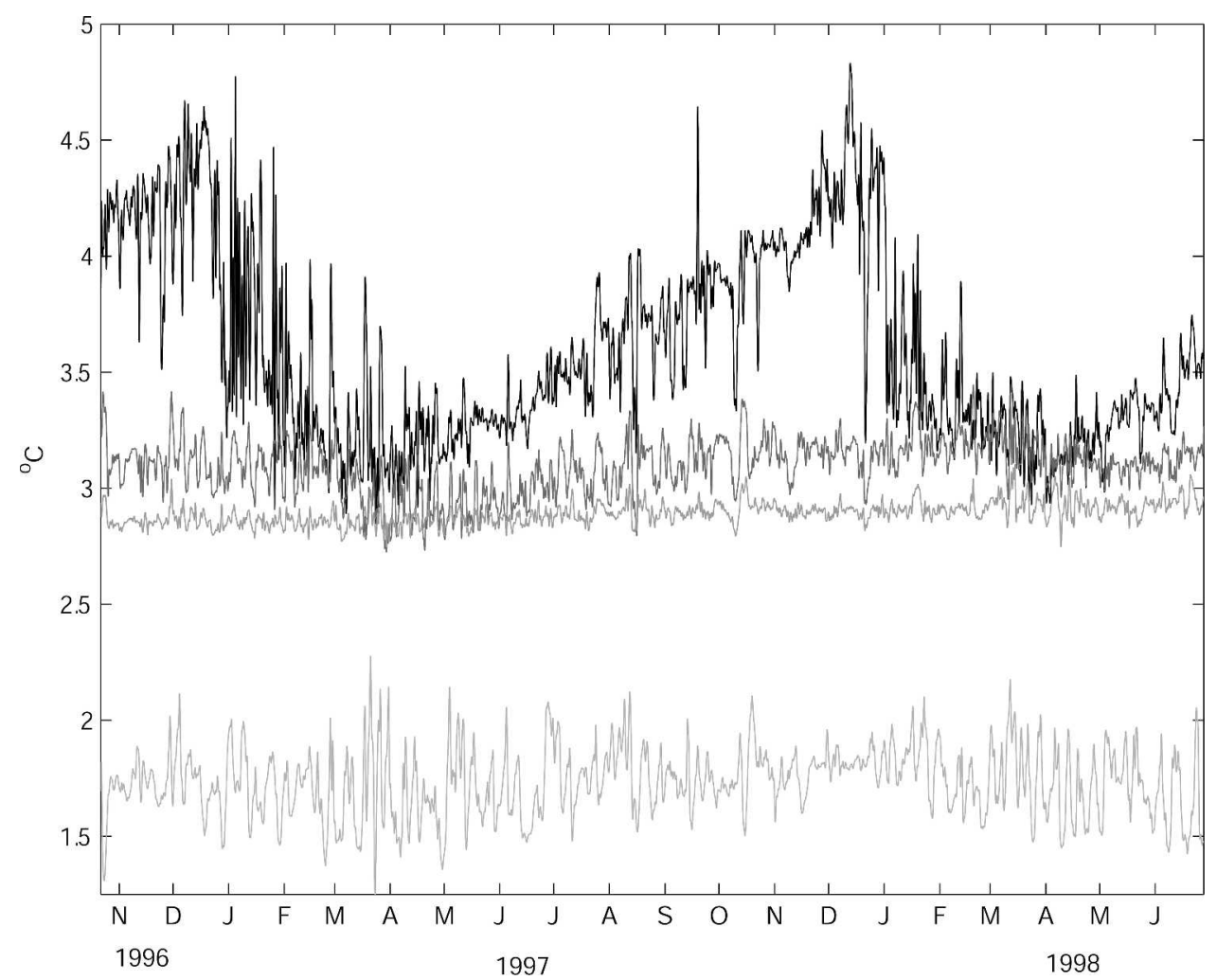

FIG. 9. Potential temperature $\left({ }^{\circ} \mathrm{C}\right)$ record (low-pass filtered with a cutoff at $27 \mathrm{~h}$ ) from the mooring B1244 located close to the 2800-m isobath above the Labrador slope (see Fig. 1). The four curves, going from darkest to lightest, correspond to the four instruments at 200,1000,1500, and $2750 \mathrm{~m}$. Monthly ticks correspond to the first day of each month.

crease in high-frequency fluctuation magnitude. If we consider that the onset can be defined with an accuracy of 6 days at each instrument, the error on the lag is about 8.5 days. The instruments depth varied by a maximum of $25 \mathrm{~m}$ during that period. Hence, the time lags suggest a deepening of the mixed layer of $10 \pm 7 \mathrm{~m}$ day $^{-1}$ and $20 \pm 9 \mathrm{~m} \mathrm{day}^{-1}$.

A $\theta-S$ diagram from the Seacat instrument record $108 \mathrm{~m}$ deep at mooring K2 summarizes the three phases of mixing in the boundary current (Fig. 12). During the first phase (December to beginning of January), most fluctuations are lateral intrusions, meandering of the current that cross isopycnals. In the second period (January-February), the variations are much more along the isopycnal lines. During that period, $\theta$ and $S$ high-frequency fluctuations compensate such that the variations in $\sigma_{0}$ are very slow similar to what was reported by Lilly et al. (1999) for the interior Labrador Sea convection. The correlation between salinity and potential temperature reaches 0.7 (significant at 95\% confidence level) during that period. The correlation goes down below 0.3 (nonsignificant at 95\% confidence level) at $384 \mathrm{~m}$ below the mixed layer. In the last period, the properties of the water column do not change much anymore except for some lateral intrusions of denser water.

\section{b. Heat loss}

We used the only CTD profiles available to compute the heat loss through the winter. First, we considered a Lagrangian approach for which we assumed that we compared approximately the same water column at the beginning and in the middle of winter at two different locations along the boundary current. The heat loss between the northern slope station on 12 November 1996 and on 6 March 1997 at Labrador slope station 106 (Fig. 1) is $4.95 \times 10^{9} \mathrm{~J} \mathrm{~m}^{-2}$ down to $1750 \mathrm{~m}$. If we consider that the water column traveled at a constant speed between the two station locations, the corresponding atmospheric heat loss is $2.18 \times 10^{9} \mathrm{~J} \mathrm{~m}^{-2}$.

Then, we considered an Eulerian approach in which we compared two CTD stations taken at the same location. The calculation for the 22 October 1996 and 6 March 1997 stations close to mooring B1244 gives 2.97 $\times 10^{9} \mathrm{~J} \mathrm{~m}^{-2}$ down to $1750 \mathrm{~m}$. One can argue that this Eulerian heat loss is a lower bound estimate because between the time of the initial station and the time the vertical mixing reaches the bottom of the warm ISW layer, the temperature of the ISW layer keeps rising (Fig. 9), adding to the buoyancy of the water column. During the same period of time, the ocean-atmosphere heat flux corresponds to $2.97 \times 10^{9} \mathrm{~J} \mathrm{~m}^{-2}$. 


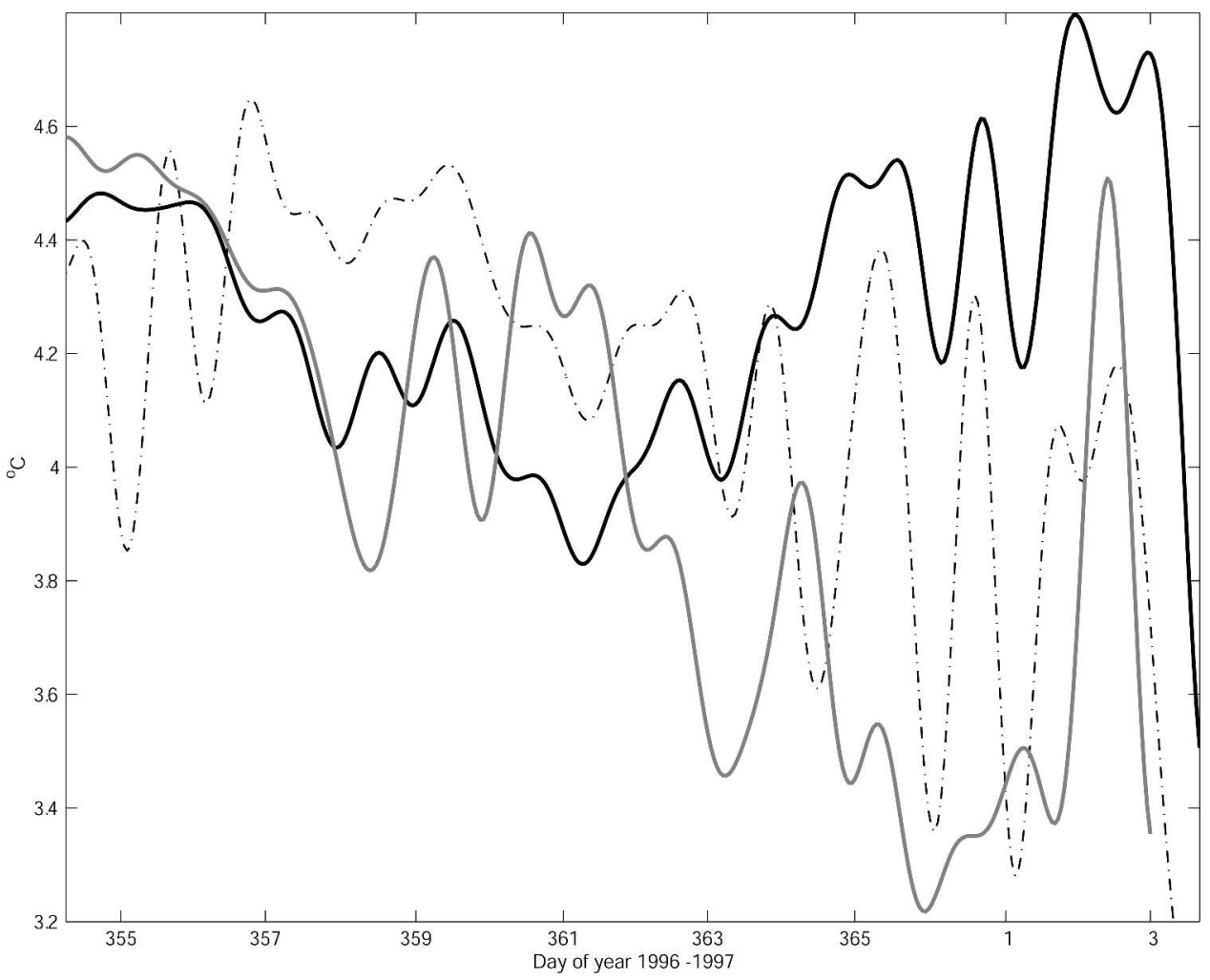

FIG. 10. Potential temperature $\left({ }^{\circ} \mathrm{C}\right)$ records (low-pass filtered with a cutoff at $27 \mathrm{~h}$ ) from the $200-\mathrm{m}$ instrument at mooring B1244 (solid gray) and the 111- (dash-dotted) and 200-m (solid black) instruments at mooring $\mathrm{K} 2$.

We computed the heat content variation for the entire cooling period from mooring B1244. Each instrument is associated with a layer of thickness given by half of the distance between the consecutive instruments. We find that the water column lost $5.58 \times 10^{9} \mathrm{~J}$ $\mathrm{m}^{-2}$ down to $2100 \mathrm{~m}$ between mid-December (max heat content) and mid-March (minimum heat content). This is close to the estimate of $4.8 \times 10^{9} \mathrm{~J} \mathrm{~m}^{-2}$ down to $2100 \mathrm{~m}$ using all the temperature records at mooring K2. During the same period, the air-sea heat fluxes accounted for a cumulative $1.9 \times 10^{9} \mathrm{~J} \mathrm{~m}^{-2}$ heat loss, which means that we need to consider other heat sinks for the boundary current (see section $4 \mathrm{~d}$ ).

\section{c. 1D model: Eulerian versus Lagrangian}

To understand better the heat balance in a boundary current water column, we ran simple Eulerian and Lagrangian 1D models. In both models, the heat lost by the mixed layer is defined by the atmospheric heat fluxes. Then, if the density profile is unstable, mixing occurs with the layers below until the profile is stable again. The 1D Eulerian mixing model is initialized with the 22 October 1996 station taken close to mooring B1244 along the AR7W line and forced with adjusted NCEP heat fluxes (Renfrew et al. 2002), with precipitation being neglected. In this case, the model does a poor job as it is not able to mix the waters much beyond the initial mixed layer (Fig. 13, top). The 1D Lagrangian vertical mixing model is initialized with the station 1 data collected above the Labrador basin northern slope on 12 November 1996, and forced with adjusted NCEP heat fluxes (Fig. 13, bottom). With this approach, we remove the along-flow lateral heat flux term from the heat balance, which cannot be done with an Eulerian approach. The column was assumed to be traveling along the $2800-\mathrm{m}$ isobath, with speeds given by a surface speed map deduced from surface drifters (Cuny et al. 2002). The Lagrangian 1D model, gives a deepening of the mixed layer of $7.9 \pm 5.8 \mathrm{~m} \mathrm{day}^{-1}$ between December 1996 and March 1997. After 136 days, the resulting mixed layer depth matches well with the observed mixed layer depth at station 106 on 6 March 1997 (114 days after the station used for initialization). However, the mixed layer is too warm, resulting in a too light mixed layer. The different result between the models can be attributed to two causes. First, the surface waters of the initial water column for the Eulerian model are much fresher, thus acting against vertical mixing. Even though the Irminger seawater layer is warmer for the Lagrangian model initial water column, the Eulerian model initial water column is more buoyant by $4 \mathrm{~m}^{2} \mathrm{~s}^{-2}$ in the top $1000 \mathrm{~m}$ because of the surface 

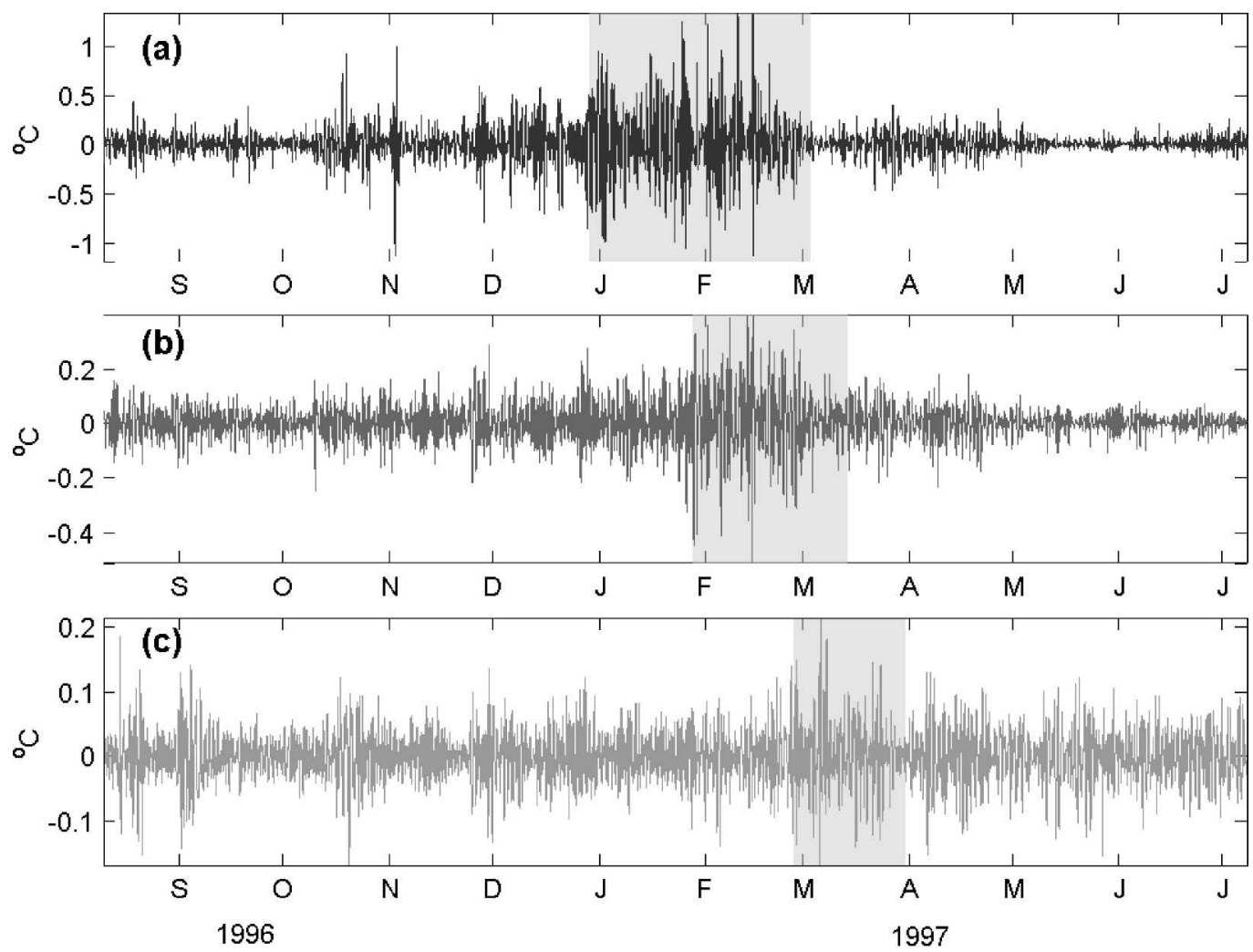

FIG. 11. High-frequency fluctuations at the (a) 108-, (b) 387-, and (c) 984-m instrument at mooring K2. High-frequency fluctuations obtained by high-pass filtering with a cutoff at $72 \mathrm{~h}$. The darker line corresponds to the shallowest instrument. The shaded areas indicate periods of high-frequency fluctuations with larger amplitude, corresponding to the convection period. Monthly ticks correspond to the first day of each month.

salinity difference. Indeed, a water column traveling in the more offshore part of the boundary current between the Greenland and Labrador coasts can spend more than three months without being covered by a significant amount of freshwater at the surface (Cuny et al. 2002). Second, the heat loss along the Lagrangian trajectory is equal to $2.77 \times 10^{9} \mathrm{~J} \mathrm{~m}^{-2}$ whereas it is only equal to $2.32 \times 10^{9} \mathrm{~J} \mathrm{~m}^{-2}$ close to B1244. There is a significant variation between the Lagrangian and Eulerian consideration because a water column starting above the northern slope goes through the northwest corner of the Labrador Basin where the highest heat fluxes are recorded every winter (Labrador Sea Group 1998). Even though the Eulerian and Lagrangian heat fluxes records present the same high heat fluxes events, there are amplitude differences in January-February that can reach 100-300 $\mathrm{W} \mathrm{m}^{-2}$. Marshall and Schott (1999) have already pointed out that Eulerian 1D mixing models are valid only over a short period of time during the convection period.

\section{d. Baroclinic instability}

Even though the Lagrangian 1D model includes one more component of the heat balance than the Eulerian model, we still found a discrepancy between the water column heat loss $\left(4.95 \times 10^{9} \mathrm{~J} \mathrm{~m}^{-2}\right)$ and the atmospheric heat fluxes $\left(2.18 \times 10^{9} \mathrm{~J} \mathrm{~m}^{-2}\right.$; see section $\left.4 \mathrm{~b}\right)$. We also found a large difference in the final temperature of the mixed layer. The differences are most likely due to across-isobath lateral processes. Along isopycnal mixing is one of them, where the vertical density profile is unchanged but the temperature and salinity can change within a density layer. Straneo et al. (2002) pointed out two other essential processes: the Ekman transport of dense offshore water and slantwise convection. However, the authors showed that their effects decrease drastically in deeper waters, each reaching below $0.1 \times 10^{-7} \mathrm{~m}^{2} \mathrm{~s}^{-3}$ in the deep Labrador Current in terms of buoyancy forcing equivalent (or $40 \mathrm{~W} \mathrm{~m}^{-2}$ in heat forcing equivalent) over a 20-day experiment. In the offshore part of the current, these forcings represented at most $20 \%$ of the atmospheric buoyancy forcing, which was equal to $10^{-7} \mathrm{~m}^{2} \mathrm{~s}^{-3}$ (or $400 \mathrm{~W} \mathrm{~m}^{-2}$ in heat forcing equivalent) in their experiment. In our case, even if we assume an additional forcing representing $20 \%$ of the atmospheric forcing, the discrepancy is still large.

In a $3 \mathrm{D}$ setup where along-current variability is observed, one must consider the role of baroclinic eddies 


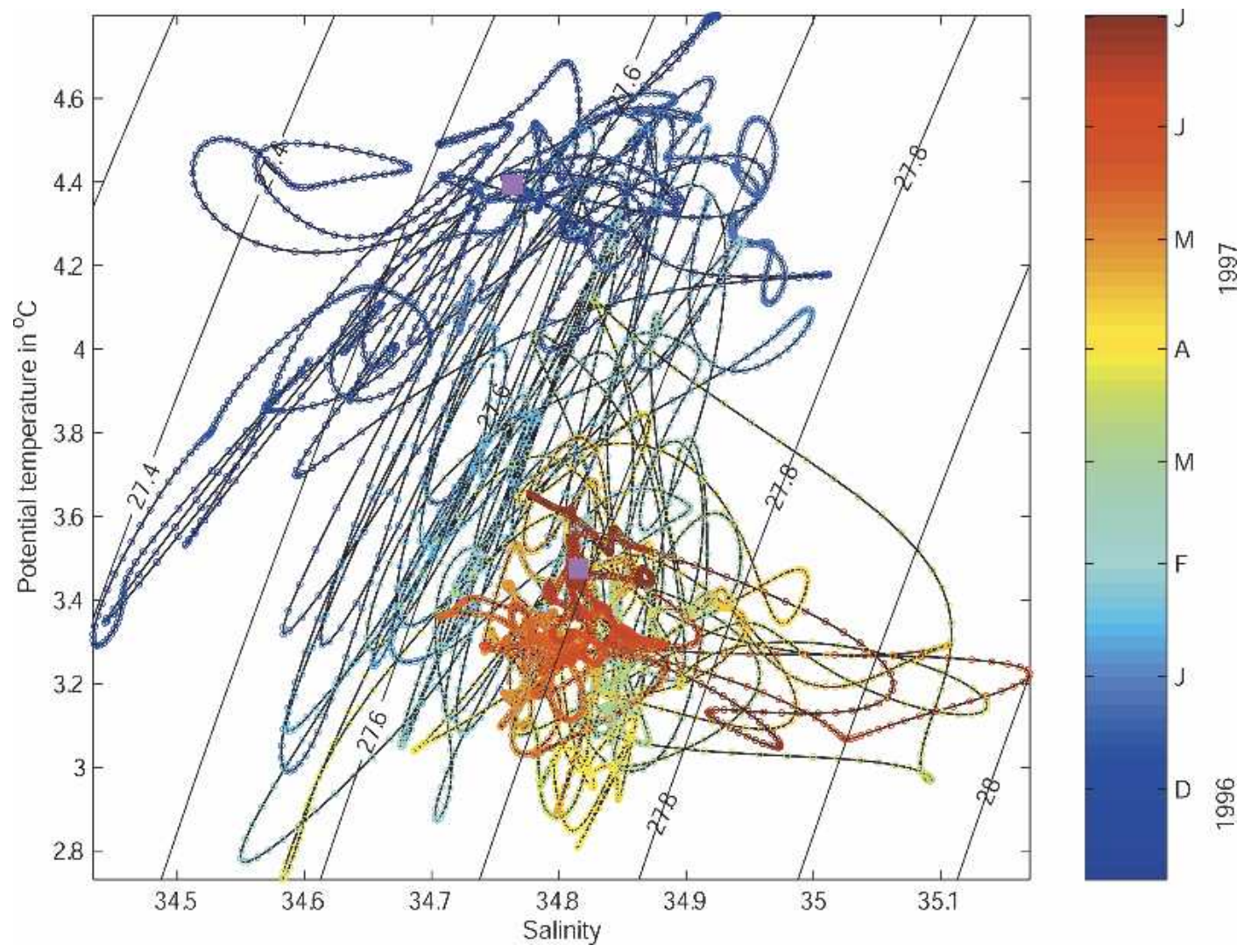

FIG. 12. A $\theta-S$ diagram for the top instrument $(108 \mathrm{~m})$ at mooring $\mathrm{K} 2$ during the convection period. The magenta squares indicate the beginning and the end of the record. The square with the warmest temperature corresponds to the beginning of the record. The color along the curve indicates time.

in transferring heat laterally (Legg et al. 1998). We have seen in section 3 that the current became increasingly unstable starting in December with a peak in MarchApril. Baroclinic instability seems to begin very soon after the onset of convection as the erosion of stratification leads to the necessary condition for instability with a ratio $l_{r} / L \rho$ (baroclinic eddy radius or front scale for us/Rossby radius of deformation) becoming large. In October 1996, within the deep Labrador Current the $l_{r} / L \rho$ ratio is close to 1.6 with $l_{r}=140 \mathrm{~km}$ and $L \rho=31.5$ $\mathrm{km}$. Note that $L \rho=N H / f$ with $N=2.5 \times 10^{-3} \mathrm{~s}^{-1}, f=$ $1.1 \times 10^{-4} \mathrm{~s}^{-1}$ and $H=1500 \mathrm{~m}$. In March 1997, $l_{r} / L \rho=$ 5.68 with $N=7 \times 10^{-4} \mathrm{~s}^{-1}$ and $L \rho=8.8$ [for a quasigeostrophic two-layer vortex $\left(l_{r} / L \rho \geq 2\right)$ is necessary condition for instability (Pedlosky 1985)]. Using the large-scale hydrography of October 1996 and March 1997, we can estimate the lateral baroclinic eddy fluxes using Visbeck et al. (1996) formula: $v^{\bar{\gamma}} \theta^{\prime}=\alpha \theta^{\overline{2}} / N$ with $\mathrm{v}^{\prime}$ the eddy across isobath velocity, $\theta$ the potential temperature, $\alpha$ a coefficient equal to $0.008, N=\sqrt{\partial \theta / \partial z}$, and $\theta^{\prime}$ the temperature anomaly of a particle displaced a distance $l_{r}$ across a zone with lateral stratification $M^{2}=\partial \theta / \partial y$. Hence, the expression can be written as

$$
v^{\prime} \theta^{\prime}=\alpha \frac{l_{r}^{2} M^{4}}{N} .
$$

We define $l_{r}$ as the length scale associated with the current width. The results are quite noisy, but multiplying the formula by $\rho \mathrm{C}_{p}$ we find out that the lateral heat fluxes by baroclinic eddies in the top $1000 \mathrm{~m}$ can reach 60-70 $\mathrm{W} \mathrm{m}^{-2}$ across the deep Labrador Current in October 1996. In March 1997, the eddy lateral heat fluxes can reach $20 \mathrm{~W} \mathrm{~m}^{-2}$ across the deep Labrador Current. High eddy flux values in October 1996 are in agreement with the high across-isobath variance observed at mooring B1244 (Fig. 7). The lower eddy flux estimate in March 1997 is more surprising as the across-isobath variance is at its peak in March 1997. But Legg et al. (1998) also suggest that the location of peak lateral eddy flux moves outward from the eddy center, that is, away from the Labrador Sea interior, in our case, through the winter. A very rough estimate of the cumulated heat loss from the deep Labrador Current can be made if we consider the lateral heat flux to be equal to $70 \mathrm{~W} \mathrm{~m}^{-2}$ in December-January and $20 \mathrm{~W} \mathrm{~m}^{-2}$ in February. The heat loss over that period for the deep Labrador Current is $0.41 \times 10^{9} \mathrm{~J} \mathrm{~m}^{-2}$. This flux estimate is not large enough to explain the discrepancy between the water column heat loss and the atmospheric heat fluxes. It is clearly necessary to find better estimates of the lateral eddy heat fluxes, but other fac- 

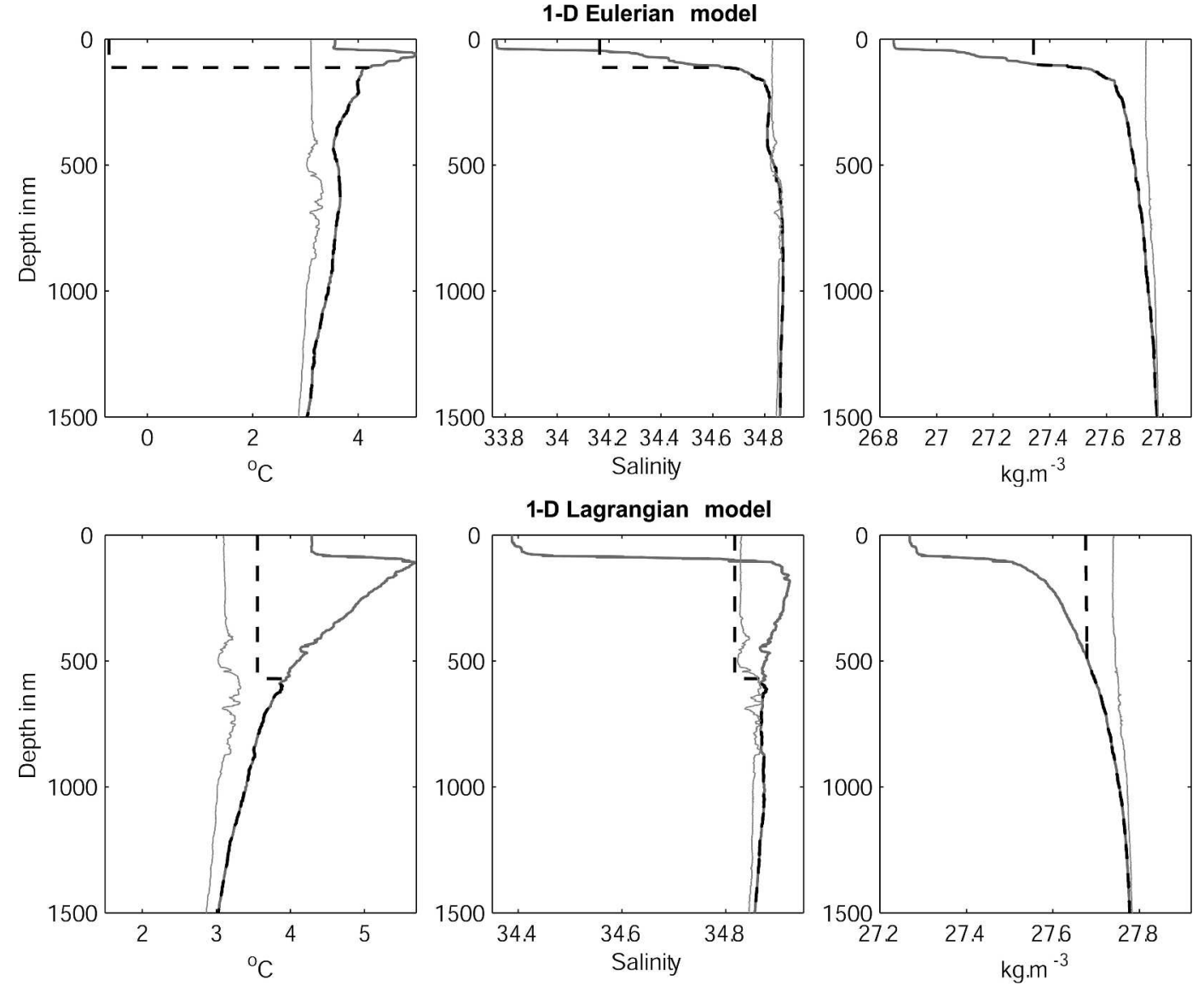

FIG. 13. (top) The 1D Eulerian model results. The initial profile (dark gray) was taken in Oct 1996 close to mooring B1244. The final profile (light gray) was taken in Mar 1997 also close to mooring B1244. The model results are shown with a dashed line. (bottom) The 1D Lagrangian model results. The initial profile (dark gray) was taken in Nov 1996 above the northern slope of the Labrador Basin (see Fig. 1 inset). The final profile (light gray) was taken in Mar 1997 close to mooring B1244. The model results are shown with a dashed line (see text for details).

tors such as local preconditioning must be taken in account.

\section{e. Localization of convection by a subducted eddy}

As described by Legg et al. (1998), eddies can localize convection by locally preconditioning the water column. Such a role could be played by blobs of wellmixed low-potential-vorticity (PV) water such as the one observed above the 2000-m isobath at station 108 between 200 and $1000 \mathrm{~m}$ (Fig. 14). It is likely to be offshore water subducted along isopycnals by processes similar to the ones described by (Spall 1995). The Labrador Current instability creates local zones of increased lateral density gradient where the flow accelerates ("frontogenesis" process). The acceleration then generates an ageostrophic cross-front circulation cell with downwelling offhsore, upwelling onshore, a subsurface flow toward the shelf, and a surface flow in the opposite direction. The subsurface flow can subduct water along isopycnals across the front. Spall (1995) described in a numerical experiment how subducted waters coming from a thicker offshore layer develop an anticyclonic vorticity to compensate for the compression due to the inshore stratification. ADCP and temperature data provide some characteristics of the observed feature (Fig. 15), which is clearly three-dimensional and not simply the signature of the upwelling component of the cross-front cell described above. The eddy has peak speeds around $10-15 \mathrm{~cm} \mathrm{~s}^{-1}$. The two velocity peaks are separated by $10 \pm 1 \mathrm{~h}$, which gives a scale of $7 \pm 4 \mathrm{~km}$ with a mean flow speed of $19.8 \pm$ $11 \mathrm{~cm} \mathrm{~s}^{-1}$ during that period. Mooring K2 is much closer to station 107 than station 108 (Fig. 1) and station 107 seems to be at the edge of the low-PV subducted water (Fig. 14). If we assume that stations 111 and 107 delimit the eddy, we deduce a radius of $12 \mathrm{~km}$ such that station 108 is very close to the eddy center. We do not observe any cyclonic feature associated with the anticyclonic one as suggested by Spall (1995). We must point out that Lilly (2003) did not observe any anticyclone-cyclone pair in his study of the Lab- 


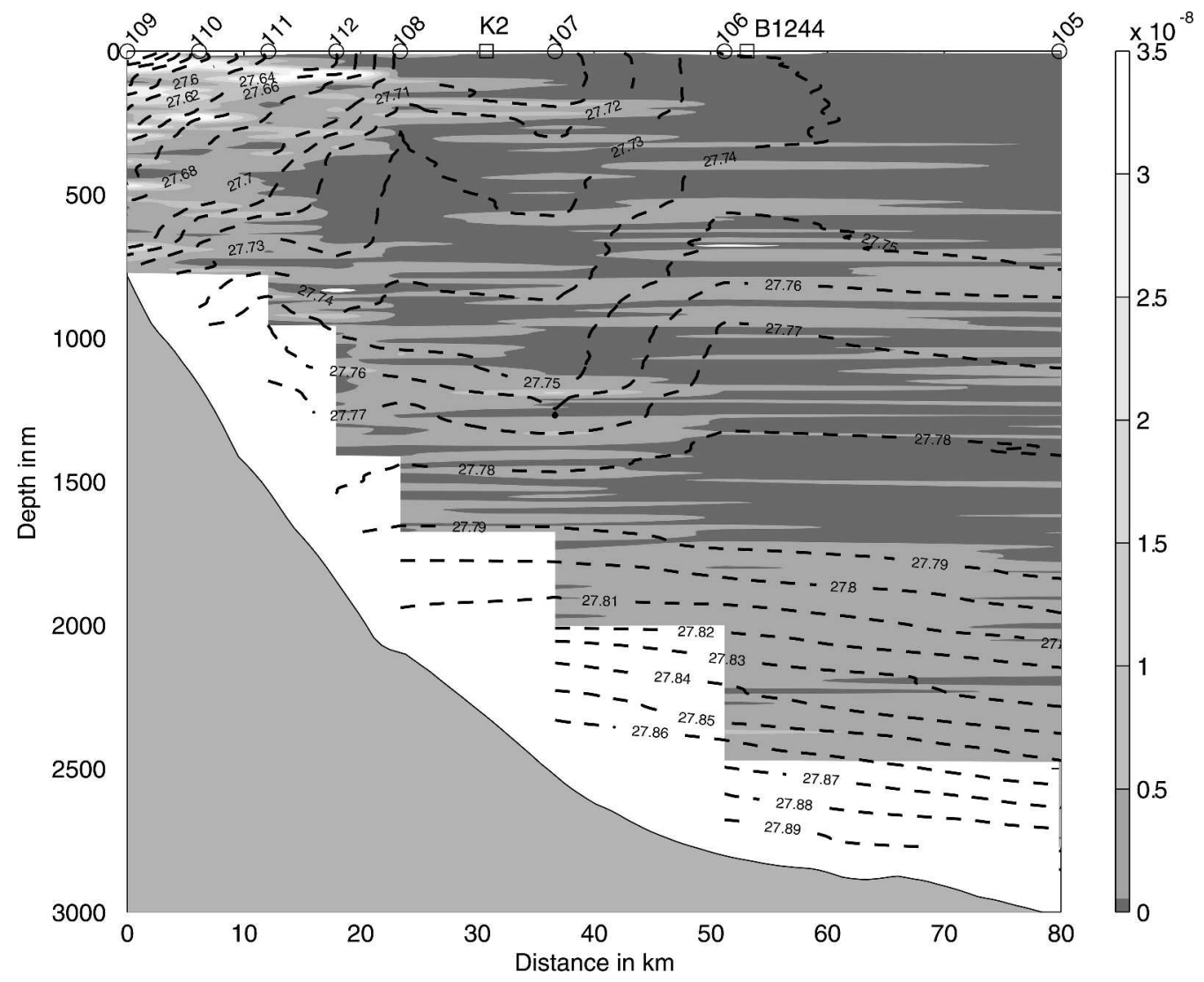

FIG. 14. Potential vorticity $\left(\mathrm{s}^{-3}\right)$ section above the Labrador slope computed from the Mar 1997 AR7W hydrographic data. Potential density $\sigma_{0}$ contours $\left(\mathrm{kg} \mathrm{m}^{-3}\right)$ are shown with dashed lines. Note the low-PV blob in the boundary current at station 108. The squares indicate the location of mooring K2 and B1244.

rador Sea eddy field. In our case, it does not mean that the cyclone is not present but simply that it could have been missed by both the CTD section and mooring $\mathrm{K} 2$.

We estimated the preconditioning effect of this lowPV blob by computing the buoyancy content difference between stations 108 and 55, a station north of station 108 close to the $2000-\mathrm{m}$ isobath. We made the calculation only between 200 and $1000 \mathrm{~m}$, the approximate vertical limits of the eddy from profile 108 . This gives a difference of $0.79 \mathrm{~m}^{2} \mathrm{~s}^{-2}$ in buoyancy, which corresponds to $3.5 \times 10^{9} \mathrm{~J} \mathrm{~m}^{-2}$ in heat loss. Hence, the effect of an eddy in changing the stratification is potentially as large as the atmospheric forcing. It is difficult to estimate the frequency of this type of feature but the work of Spall (1995) emphasizes the necessary meandering of the frontal current to obtain such eddies. The Labrador Current often meanders, as suggested by the offshore water intrusions in Fig. 8. Thus, we can expect to observe low-PV water eddies as soon as the interior mixed layer is thicker than the boundary isopycnal layers, which are at most $100-150$ m thick. We ought to consider, though, that according to Spall's experiment the eddies tend to move onshore across the front, which makes their "preconditioning" effect time limited.

\section{f. The final period}

Finally, a portion of the current that has been constantly forced through the winter flows along the mooring. The mooring B1244 measured an almost constant temperature at 200 and $1000 \mathrm{~m}$ for approximately 40 days. If we assume that the mean deep Labrador Current speed is $20 \mathrm{~cm} \mathrm{~s}^{-1}$ during that period, the wellhomogenized portion of current was $690 \mathrm{~km}$ long. This distance covers a significant portion of the deep Labrador Current from $59.5^{\circ} \mathrm{N}$ to the mooring location $\left(55.47^{\circ} \mathrm{N}, 53.65^{\circ} \mathrm{W}\right)$ along the $2800-\mathrm{m}$ isobath.

During the winter 1996/97, the potential temperatures at the 200- and 1000-m instruments were equal from mid-February until the end of March and from mid-February until the end of April during the winter 1997/98. These observations suggest that the water column above the lower Labrador slope became homogeneous over a depth close to $1000 \mathrm{~m}$ at the end of winter. The AR7W winter section shown by Pickart et al. (2002) is representative of the final state of the stratification above the Labrador slope after the convection 


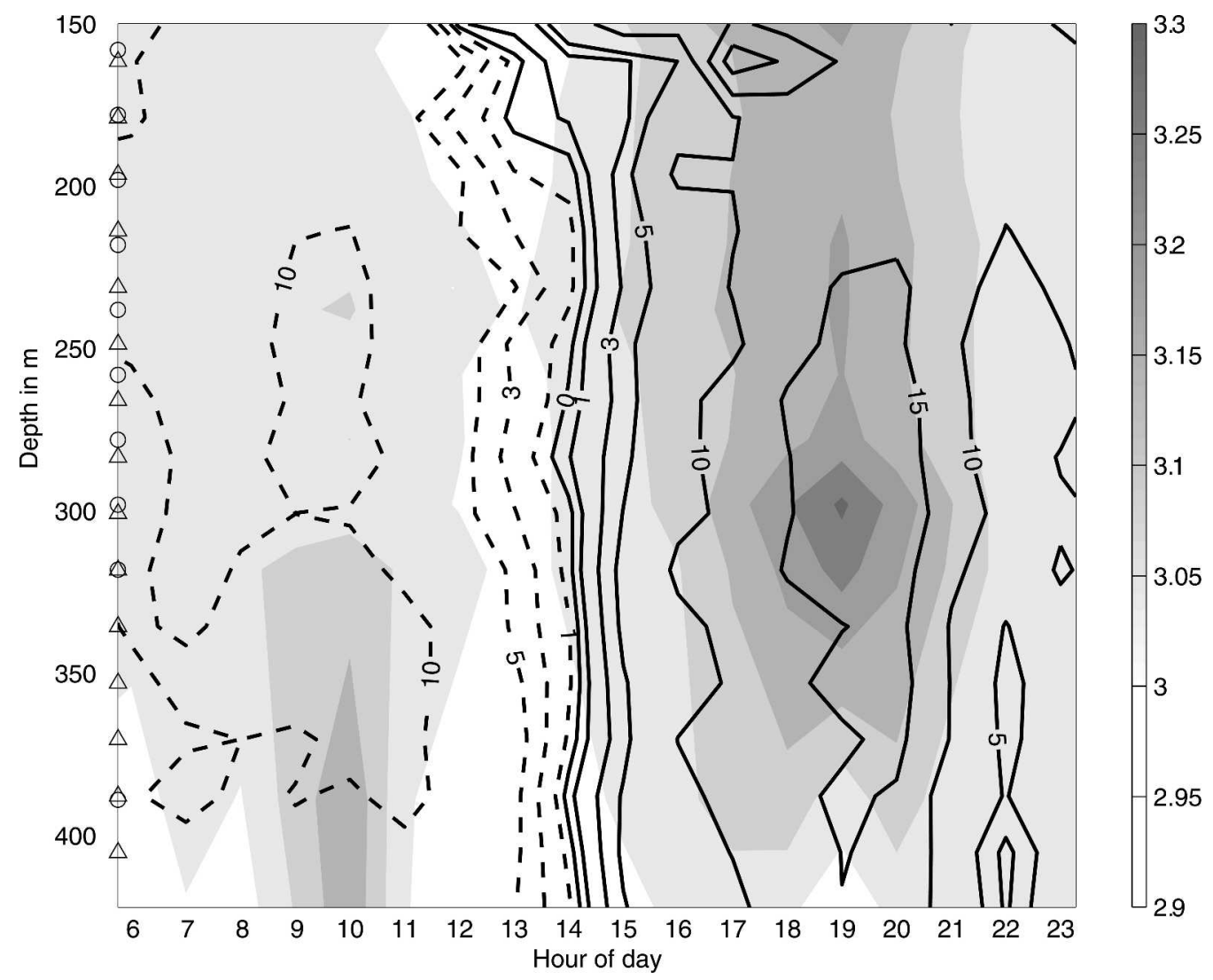

FIG. 15. Across-mean-flow velocity (black contours; $\mathrm{cm} \mathrm{s}^{-1}$ ) from ADCP data at mooring $\mathrm{K} 2$ at the time of the low-PV blob observed in Fig. 14. The feature is an anticyclonic eddy showing first a negative across-isobath velocity. Potential temperature $\left({ }^{\circ} \mathrm{C}\right)$ is shown in the background. The circles indicate the location where temperature is available, and the triangles indicate the center of the bins where velocity is provided by the upward-looking ADCP from K2 at $440 \mathrm{~m}$.

period as the mooring shows that the temperature stopped decreasing shortly before the section date. Moreover, at mooring $\mathrm{K} 2$, the maximum mixed layer density of $27.75 \mathrm{~kg} \mathrm{~m}^{-3}$ was observed simultaneously at the two top instruments (108 and $384 \mathrm{~m}$ ) between 20 February and 14 March 1997, while Pickart et al. (2002) reported a 700-m-deep mixed layer depth close to these instruments on 5 March. The density at $984 \mathrm{~m}$ at mooring $\mathrm{K} 2$ always stayed slightly larger $\left(27.78 \mathrm{~kg} \mathrm{~m}^{-3}\right)$ than at these two instruments, suggesting that the mixed layer depth was between 400 and $1000 \mathrm{~m}$.

The warming period following the convection period is slow and takes place during spring, summer, and autumn (Fig. 9). Part of the length of recovery may be seen as an indicator of the length of boundary current strip, which has been affected by mixing throughout winter and spring upstream of the moorings. In addition to the processes described above, the number of warm core eddies shed by the West Greenland Current increases significantly from March to June, as seen from altimetry data (Lilly 2003), leading to a large loss of warm water from the current. Finally, winter mixing in the Irminger Basin western boundary current, up- stream of our region of interest, is also a factor affecting the return of the warmest North Atlantic Water at mooring B1244 (Pickart et al. 2002, 2003).

\section{Mixing above the upper Labrador slope}

The processes taking place above the shelf break during winter are slightly different from the ones above the deeper part of the continental slope. The mixing begins at a later stage in winter above the shelf break, for instance. However, they also share similarities such that the March 1997 CTD casts above the shelf break can give us an idea of what took place in December 1996 above the lower continental slope.

\section{a. Slanting of the isopycnals}

Close to the shelf break, the vertical and horizontal stratification observed in winter is weaker than in the autumn but remains significant (Fig. 16, top). We note that the ISW core shifts upward as the isopycnals steepen: the $3.8^{\circ} \mathrm{C}$ isotherm delimiting the ISW in October 1996 is found between 300 and $600 \mathrm{~m}$, while a remnant of ISW in March 1997 is delimited by $3.6^{\circ} \mathrm{C}$ 

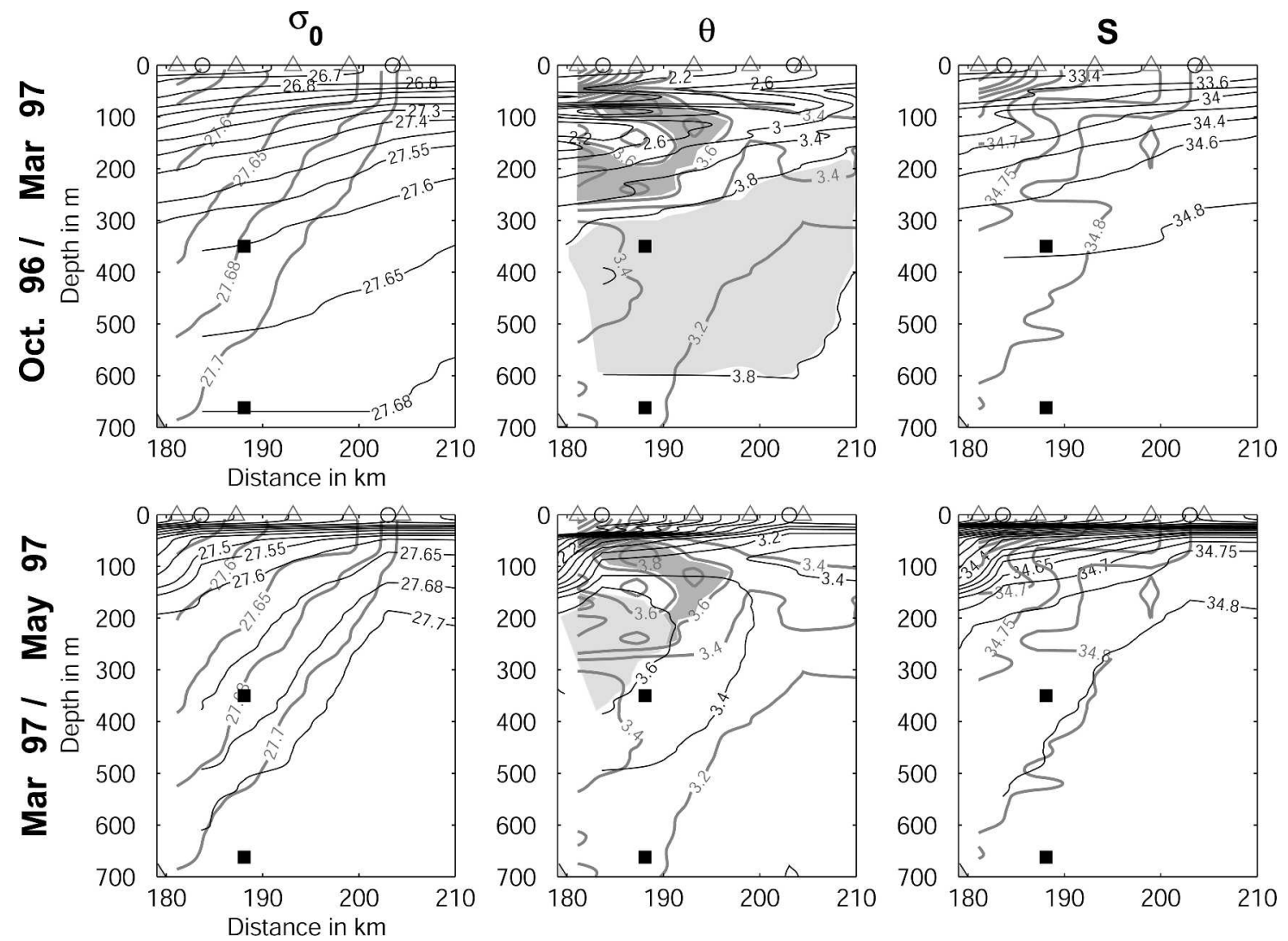

FIG. 16. (top) Comparison of the Oct 1996 (black contours) and Mar 1997 (gray contours) hydrographic data. (top left) Potential density $\sigma_{0}\left(\mathrm{~kg} \mathrm{~m}^{-3}\right)$, (top middle) potential temperature $\left({ }^{\circ} \mathrm{C}\right.$ ), and (top right) salinity. (bottom) Comparison of the May 1997 (black contours) and Mar 1997 (gray contours) hydrographic data. (bottom left) Potential density $\sigma_{0}(\mathrm{~kg}$ $\mathrm{m}^{-3}$ ), (bottom middle) potential temperature $\left({ }^{\circ} \mathrm{C}\right.$ ), and (bottom right) salinity. The areas corresponding to the ISW are shaded for each section. The black squares indicate the instrument locations on mooring K6.

between 70 and $280 \mathrm{~m}$. This is most likely the reason why the temperature at $350 \mathrm{~m}$ at $\mathrm{K} 6$ is quite constant over November 1996 but starts rising during December and January (Fig. 4a).

The March 1997 stratification reveals that the common temperature observed at 350 and $662 \mathrm{~m}$ at $\mathrm{K} 6$ is not due to a water column vertically mixed from the surface. Instead, it is simply the increase in isopycnal slope that decreases the stratification between instruments. The weakening of the vertical stratification could be due to the onshore shift of the "classical" Labrador Current. The Labrador Current, mostly buoyancy driven, is weak in winter and weakest in March-April when the freshwater influx on the Labrador shelf is the weakest (Lazier and Wright 1993). Vertical mixing taking place offshore could also be responsible for the isopycnal shift. The fact that cooling at K6 starts after cooling at K2 or B1244 supports this idea (Fig. 4).

We also plotted the shelfbreak CTD profiles on a $\theta-S$ diagram to show the changes within each isopycnal layer (Fig. 17). The ISW core is not much cooled through the winter until an along-isopycnal intrusion occurs (look at the winter edges of the ISW at 27.6 and $\left.27.66 \sigma_{0}\right)$. We can trace this intrusion observed at station 109 in the range $27.61-27.63 \sigma_{0}$ back to the surface at station 111 where the isopycnal outcrops. The alongisopycnal subduction of surface water could be the result of the cross-front ageostrophic flow described in section 4c (Pollard and Regier 1992). The most remarkable changes occur below the ISW layer, below $27.68 \sigma_{0}$ (Fig. 17). The density layer 27.68-27.74 $\sigma_{0}$ is homogeneous in temperature and salinity in March and May 1997. Along-isopycnal intrusions could be responsible for the necessary mixing. However, a warm and salty peak marking the return of ISW above $27.68 \sigma_{0}$ is seen in May 1997 soon after the end of the convection period, suggesting that along isopycnal intrusions into the current did not occur enough to wipe out the warm core uniformly along the current. On the other hand, the 27.68-27.74 $\sigma_{0}$ layer barely changes from March to May, suggesting that more intense mixing affects it.

At the end of the convection period, the isopycnals become less steep, particularly above $200 \mathrm{~m}$, such that the ISW core (delimited by the $3.6^{\circ} \mathrm{C}$ contour in March and May 1997) returns closer to its October 1996 depth (Fig. 16, bottom). The K6 instruments still show com- 


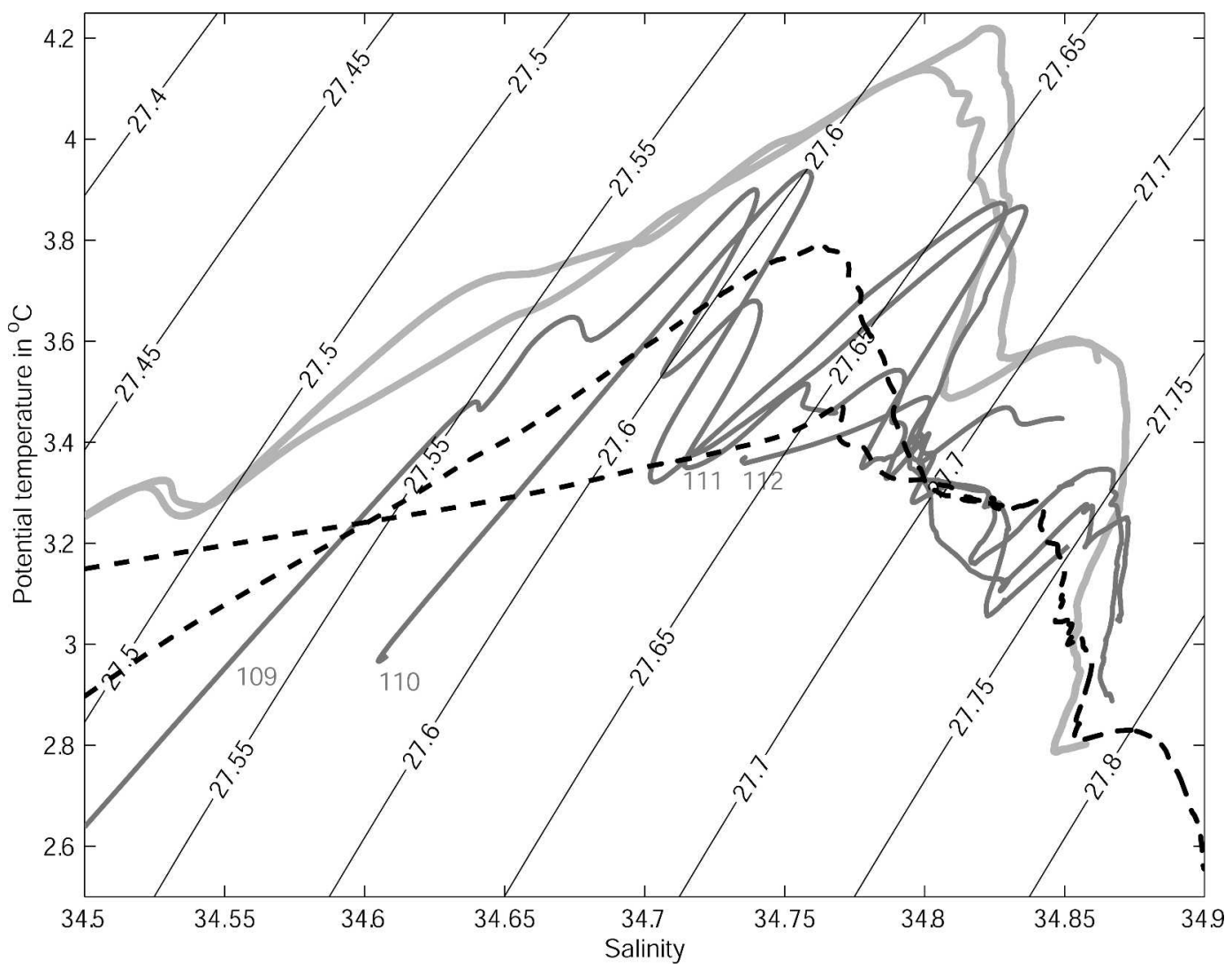

FIG. 17. A $\theta-S$ diagram showing Labrador shelfbreak profiles from the Oct 1996 (solid light gray), Mar 1997 (solid dark gray), and May 1997 (black dashed) AR7W hydrographic sections. The station numbers corresponding to the Mar 1997 profiles are indicated.

mon temperatures at 350 and $662 \mathrm{~m}$ in May 1997 because the instruments are below $350 \mathrm{~m}$ where the stratification has not changed much from winter to spring. At that point, restratification has only affected the surface where freshwater appears.

\section{b. Baroclinic instability}

While the change in stratification could be due to a lateral shift in the boundary current (see above), baroclinic instability most likely plays a prominent role. Similarly to what we described for the deeper part of the continental slope, the instability allows for mixing above the shelf break while maintaining a significant vertical stratification.

Using the autumn 1996 and winter 1997 CTD sections, we computed the available potential energy (APE) close to the shelf break. We can only consider an Eulerian approach for this calculation because there are no data available at the $1000-\mathrm{m}$ depth above the northern Labrador slope. The available potential energy is a measure of the energy stored during the convection period, but it is also a measure of the energy available for sustaining baroclinic instability and an indicator of the instability growth (Gill 1982). It is com- puted as the difference between the potential energy of the section and the state of minimum energy obtained by the redistribution of the CTD section bins in a horizontally homogeneous stable stratification. We concentrated our study on the region close to the shelf break, above $800 \mathrm{~m}$, in the core of the classical Labrador Current. We observe in February 1997 an increase in APE by $1-2.1\left(\times 10^{17} \mathrm{~kg} \mathrm{~s}^{-2}\right)$ from the October 1996 APE $(8$ $\times 10^{15}$ to $3 \times 10^{16} \mathrm{~kg} \mathrm{~s}^{-2}$ ), depending on the resolution of the density layers defined to rearrange the stratification. The increase is in agreement with the increase in eddy kinetic energy from autumn to winter-spring.

Using the same method as described for the deep Labrador Current, we estimated the lateral eddy heat fluxes close to the shelf break using the hydrographic data. These fluxes can reach $8 \mathrm{~W} \mathrm{~m}^{-2}$ in October 1996 and $40 \mathrm{~W} \mathrm{~m}^{-2}$ in March 1997. If we consider that the fluxes remain at $8 \mathrm{~W} \mathrm{~m}^{-2}$ in December-January and 40 $\mathrm{W} \mathrm{\textrm {m } ^ { - 2 }}$ in February, the cumulated heat loss reaches $0.14 \times 10^{9} \mathrm{~J} \mathrm{~m}^{-2}$.

\section{c. Slantwise convection}

Mixing while the stratification remains significant also suggests the possibility of slantwise convection. 


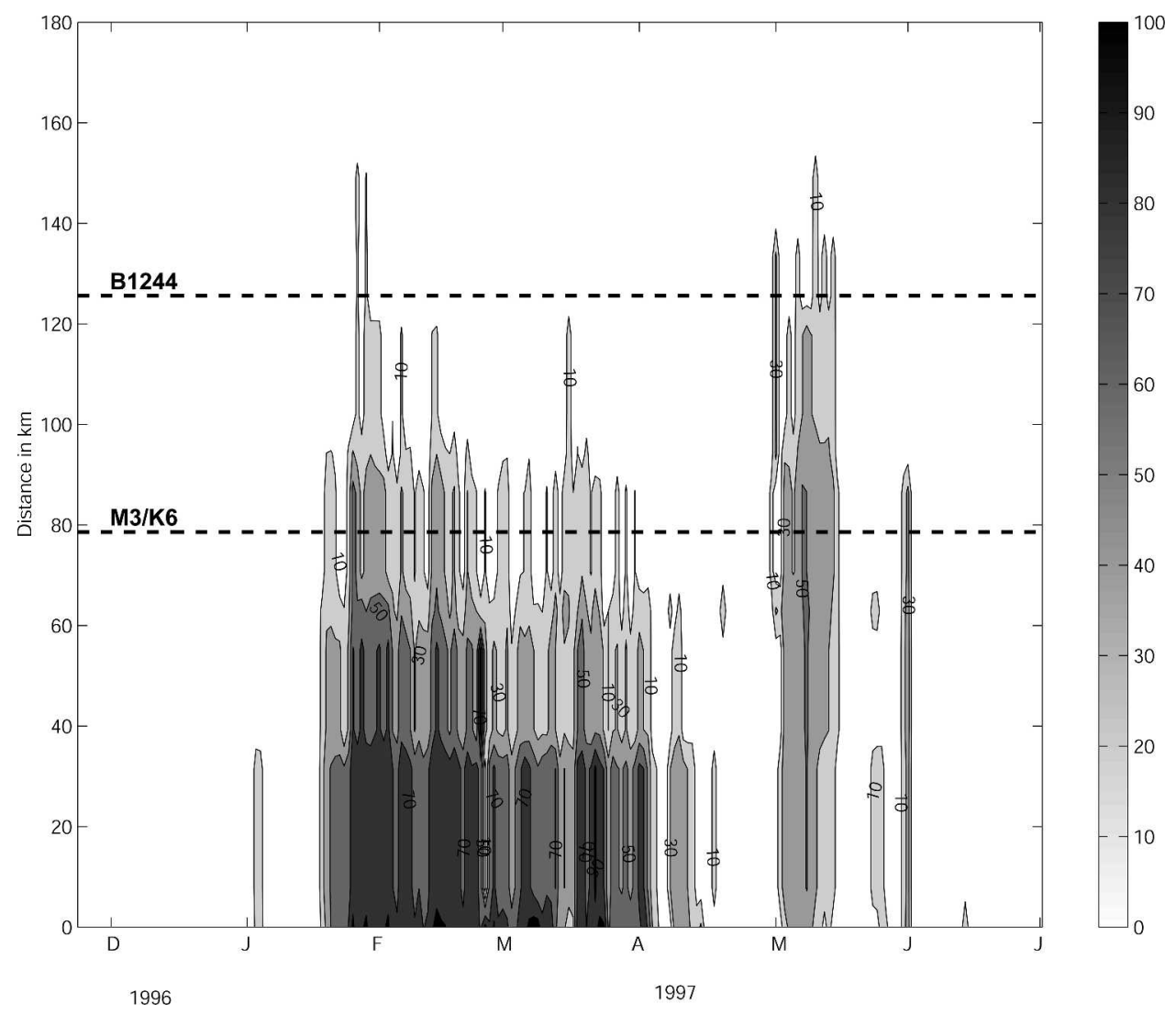

FIG. 18. Time evolution of sea ice concentration (\%) across the AR7W line during 1996/97. The location of mooring K6/M3 and B1244 are shown with dashed lines. Monthly ticks correspond to the first day of each month.

Even though the conditions seem ideal for slantwise convection, we were not able to find clear evidence for it. We did not find any region of negative PV associated with a stable stratification in the winter CTD sections (Fig. 14). This is supposed to be a necessary condition for symmetric instability, which would lead to slantwise convection. Let us define the potential vorticity in a two-dimensional plane perpendicular to the Labrador Current direction by $\mathrm{PV}=B_{y}\left(U_{z}+f^{*}\right)+B_{z}\left(f-U_{y}\right)$ with $B$ the buoyancy $\left[B=-g\left(\rho-\rho_{0}\right) / \rho_{0}\right], U$ the alongshore mean flow, and $f$ and $f *$ the vertical and horizontal Coriolis components. We could not compute the lateral velocity gradient, but this would not change our result because $-U_{y}$ is positive on the offshore side of the shelfbreak Labrador Current. In our case, the lateral buoyancy gradient is always negative and the vertical gradient is mostly positive. From the March CTD section, we find the lateral buoyancy gradient to be about $-1.5 \times 10^{-7} \mathrm{~s}^{-2}$, which is not enough to create a significant region of negative PV (Fig. 14) as the vertical gradient is one order of magnitude larger. The only regions of negative PV observed were associated with regions of unstable stratification close to the surface. However, Straneo (1999) was not able to observe such regions of symmetric instability in her model even though she observed active slantwise convection. Hence, with the currently available data, we cannot affirm that slantwise convection is taking place close to the shelf break. We suggest that the data coverage should be close to the plume scale $(1 \mathrm{~km})$ to have better chances of tracking slantwise convection. As baroclinic instability begins quite soon after the onset of convection and symmetric instability, it is possible that baroclinic instability takes over and undermines the role of symmetric instability. In a 3D setup where absolute momentum is not necessarily conserved and baroclinic instability will tend to restratify the water column, the alignment of the absolute momentum lines with the isopycnal lines is not expected.

\section{d. Additional forcing terms: Ekman transport and sea ice}

In terms of forcing, the Ekman transport of buoyancy from offshore is largest in that region because the lateral density gradient is the largest (Straneo et al. 2002). It can be as large as one third of the atmospheric forcing. However, it is difficult to quantify its role because a time series of the surface density field would be necessary. Another cooling source has been pointed out by Boyd and D'Asaro (1994) who showed that ice is a 

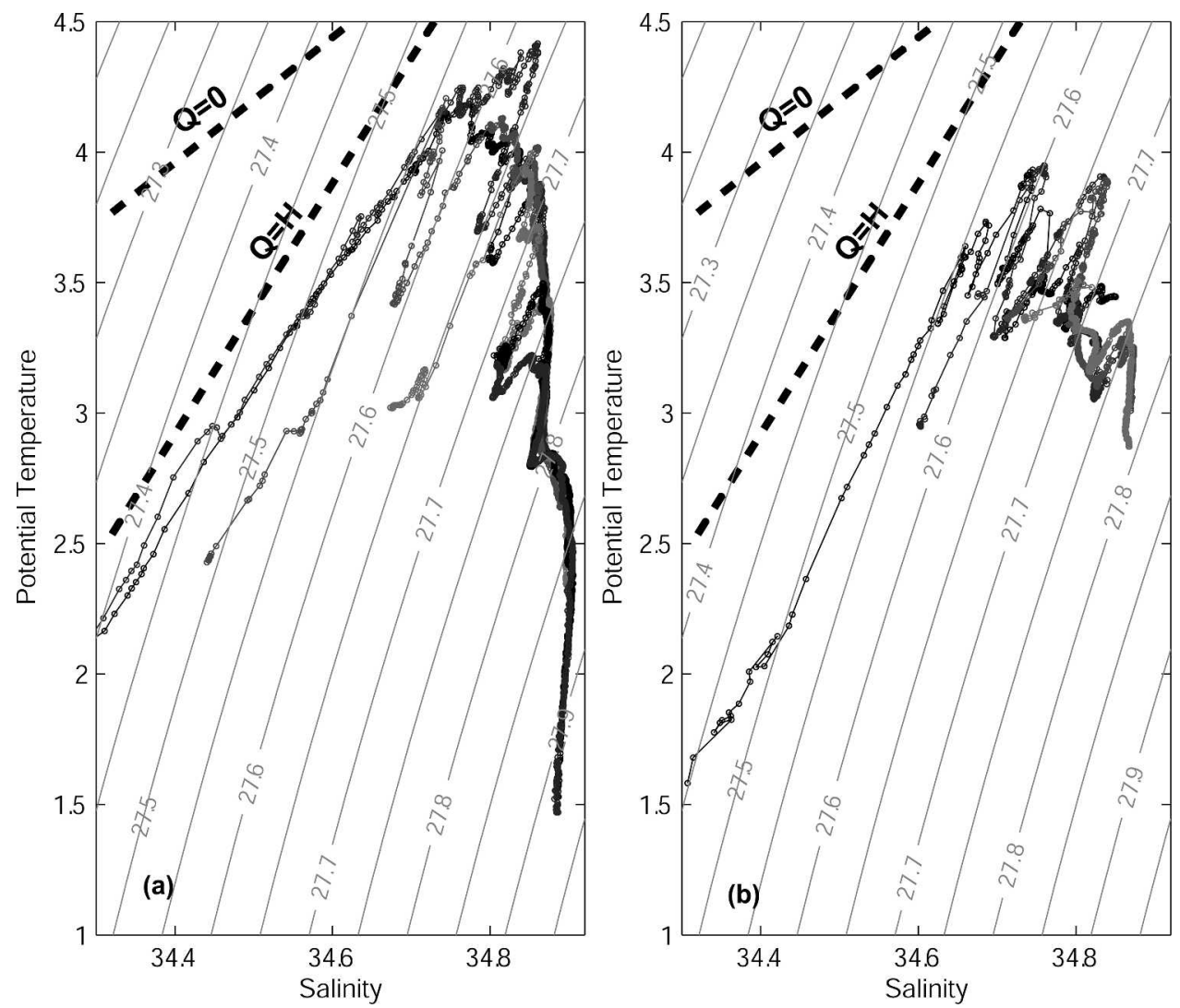

FIG. 19. A $\theta-S$ diagram for the (a) middle and (b) southern section shown in Fig. 1. The dashed lines indicate the theoretical $\theta-S$ slope for a stratification due to cooling by ice only $(Q=0)$ and equally by the atmosphere and the ice $(Q=H)$. See text for details.

major heat sink for the warm core of the West Spitsbergen Current and greatly influences the water mass observed above the continental slope. Close to the shelf break, along the AR7W line (Fig. 18), the ice concentration reached $40 \%$ in February 1997. Boyd and D'Asaro (1994) demonstrated that the $\theta-S$ relation in such an environment is given by $d T / d S \approx 2.4[(Q / H)+$ 1] with $Q$ the heat lost to the atmosphere and $H$ the heat lost to the ice. Throughout winter, ice advected from upstream or from the shelf will flow above outcropping isopycnals corresponding to the ISW layer. This will lead to the melting of the ice, that is, the cooling of the ISW and the freshening of the surface waters. At the two southernmost sections shown in Fig. 1 , the stations between the isobath 2000 and $1000 \mathrm{~m}$ show a stratification that could be due to heat lost in equal amounts to the atmosphere $(Q)$ and to the ice (H) (Fig. 19).

\section{Summary}

Using hydrographic data and several moorings, we analyzed the processes taking place in winter within the Labrador Current. Even though the temperature time series from several moorings across the Labrador slope and the interior suggest that vertical mixing takes place in a very similar fashion at all of these locations, we found that the processes differ slightly.

Above the lower Labrador slope, we showed that the observed denser waters are the result of active vertical mixing similar to the open ocean convection and not due to the advection of offshore waters. We found that a Lagrangian 1D mixing model does a better job at reproducing the mixed layer depth than an Eulerian one. However, the discrepancy between the water column heat loss and the atmospheric forcing, as well as the poor job the Lagrangian model does at reproducing the mixed layer temperature, emphasize the importance of lateral interactions between the interior and the boundary current. These interactions include alongisopycnal mixing, baroclinic eddy fluxes and cross-front subduction of eddies toward the shore. We estimated the baroclinic eddy heat fluxes toward offshore and found some evidence of the subduction of an eddy of low-PV interior water. That eddy modified the boundary current stratification, hence enabling deeper vertical overturning. This might not be that different from the interior where eddies locally precondition convec- 
tion and might be a preferential location for plume development (Legg et al. 1998).

The change in stratification closer to the shelf break is a combination of current dynamics, along-isopycnal mixing, baroclinic eddy fluxes, and possibly slantwise convection. The common temperature observed at several instruments above the shelf break is the result of an increase in isopycnal slope rather than a real vertical homogenization of the water column all the way from the top. We suggest that the onshore move of the isopycnals is due in part to the onshore shift of the shelfbreak Labrador Current. The ISW core is not totally mixed away during the winter but displaced with the onshore shift of the isopycnals. For density layers lighter than $27.68 \sigma_{0}$, along-isopycnal intrusions seem to be the main mixing factor. In the layer below, $27.68-27.74 \mathrm{~kg}$ $\mathrm{m}^{-3}$, more intense mixing occurs throughout the winter while the vertical and horizontal stratification remains significant. This leads us to think that similarly to the mixing above the lower continental slope, baroclinic eddy fluxes are essential to maintain the stratification. Interestingly, that density layer corresponds to the density of the lens of Upper Labrador Sea Water observed downstream by Pickart et al. (1997). Slantwise convection is also a potential candidate for generating mixing while maintaining a significant stratification. However, we were not able to observe direct evidence of slantwise convection because of the low lateral resolution of the available data and the overwhelming role of baroclinic instability. Close to the shelf break, both the Ekman transport of denser offshore waters and the cooling by sea ice constitute additional forcing sources.

The timing for the onset of mixing is very much dependant on the location. The winter cooling is observed first at B1244, then at K2, then at Bravo, and finally at K6/M3 (Fig. 4). Mooring B1244 is in the middle between the region of most intense atmospheric forcing at the ice edge and the region of weaker stratification offshore. Slightly onshore at K2, the water column is more stratified, hence mixing begins later. Mooring BRAVO is next as the stratification is weak but it is far from the region of highest heat fluxes in comparison with the lower continental slope moorings. Finally, mooring K6/ M3 is last as it is in the region with the strongest stratification.

We also notice that the 1000-m-deep temperature at mooring B1244 keeps decreasing even after the temperature at $200 \mathrm{~m}$ has stabilized around $3.15^{\circ} \mathrm{C}$ in midMarch. The $1000 \mathrm{~m}$ temperature cools to a temperature similar to the ones observed at $1500 \mathrm{~m}\left(2.8^{\circ}-2.85^{\circ} \mathrm{C}\right)$, but the $1000-\mathrm{m}$ record presents much more variability such that we surmise that the column is not homogeneous from $1000 \mathrm{~m}$ to $1500 \mathrm{~m}$. We do not observe such cooling in the $\mathrm{K} 2$ mooring record. The cold water could be intrusion of Labrador seawater from the interior into the boundary current. However, the product of convection observed at the end of the 1996/97 winter is mostly found above $1000 \mathrm{~m}$ and is closer to $3^{\circ} \mathrm{C}$ in temperature (Fig. 2). This leads us to think that the water mass advected in the boundary current is "older" Labrador seawater formed during the strong convection that took place at the beginning of the 1990s and that reached as deep as $2 \mathrm{~km}$ (Lilly et al. 1999). If such a scenario is valid, it seems that the advection of the interior convection product is most active at the end of winter when the current is most unstable (see section 3). An analysis of the interior-boundary eddy transport is beyond the scope of this study, but it is clear that one would have to consider the seasonality of these interactions.

Acknowledgments. The authors thank Fiammetta Straneo for her helpful insights on the subject of slantwise convection, Luanne Thompson for her thorough editing of this manuscript, and two reviewers for their constructive comments.

\section{REFERENCES}

Boyd, T., and E. D'Asaro, 1994: Cooling of the west Spitsbergen current: Wintertime observations west of Svalbard. J. Geophys. Res., 99, 22 597-22 618.

Cuny, J., P. B. Rhines, P. P. Niiler, and S. Bacon, 2002: Labrador Sea boundary currents and the fate of the Irminger Sea Water. J. Phys. Oceanogr., 32, 627-647.

Eden, C., and C. Böning, 2002: Sources of eddy kinetic energy in the Labrador Sea. J. Phys. Oceanogr., 32, 3346-3363.

Gill, A. E., 1982: Atmosphere-Ocean Dynamics. Academic Press, $662 \mathrm{pp}$.

Kawase, M., 1987: Establishment of deep ocean circulation driven by deep-water production. J. Phys. Oceanogr., 17, 2294-2317.

Labrador Sea Group, 1998: The Labrador Sea Deep Convection Experiment. Bull. Amer. Meteor. Soc., 79, 2033-2058.

Lavender, K. L., R. E. Davis, and W. B. Owens, 2000: Mid-depth recirculation observed in the interior Labrador and Irminger seas by direct velocity measurements. Nature, 407, 66-69.

Lazier, J. R. N., and D. G. Wright, 1993: Annual velocity variations in the Labrador Current. J. Phys. Oceanogr., 23, 659678.

_ R. Hendry, A. Clarke, I. Yashayaev, and P. Rhines, 2002: Convection and restratification in the Labrador Sea, 19902000. Deep-Sea Res., 49A, 1819-1835.

Legg, S., J. McWilliams, and J. Gao, 1998: Localization of deep ocean convection by a mesoscale eddy. J. Phys. Oceanogr., 28, 944-970.

Lilly, J., 2003: Observations of the Labrador Sea eddy field. Progress in Oceanography, Vol. 59, Pergamon, 75-176.

— , P. B. Rhines, M. Visbeck, R. Davis, J. R. Lazier, F. Schott, and D. Farmer, 1999: Observing deep convection in the Labrador Sea during winter 1994/95. J. Phys. Oceanogr., 29, 2065-2098.

Marshall, J., and F. Schott, 1999: Open-ocean convection: Observations, theory and models. Rev. Geophys., 37, 1-64.

Molinari, R. L., R. A. Fine, W. D. Wilson, R. G. Curry, J. Abell, and M. S. McCartney, 1998: The arrival of recently formed Labrador Sea Water in the Deep Western Boundary Current at $26.5^{\circ}$ N. Geophys. Res. Lett., 25, 2249-2252.

Pedlosky, J., 1985: The instability of continuous heton clouds. $J$. Atmos. Sci., 42, 1477-1486.

Pickart, R., M. Spall, and J. Lazier, 1997: Mid-depth ventilation in the western boundary current system of the sub-polar gyre. Deep-Sea Res., 44, 1025-1054.

— D. D. Torres, and R. A. Clarke, 2002: Hydrography of the 
Labrador Sea during active convection. J. Phys. Oceanogr., 32, 428-457.

_ , F. Straneo, and G. Moore, 2003: Is Labrador Sea water formed in the Irminger Basin? Deep-Sea Res., 50, 23-52.

Pollard, R., and L. Regier, 1992: Vorticity and vertical circulation at an ocean front. J. Phys. Oceanogr., 22, 609-625.

Renfrew, I. A., G. W. K. Moore, P. S. Guest, and K. Bumke, 2002: A comparison of surface layer and surface turbulent flux observations over the Labrador Sea with ECMWF analyses and NCEP reanalyses. J. Phys. Oceanogr., 32, 383-400.

Rhein, M., and Coauthors, 2002: Labrador Sea Water: Pathways, CFC inventory, and formation rates. J. Phys. Oceanogr., 32, 648-665.

Rhines, P., and J. Lazier, 1995: A 13-year record of convection and climate change in the deep Labrador Sea. Proc. PI's Meeting, University Corporation for Atmospheric Research Atlantic Climate Change Program, Miami, FL, NOAA, 5055 .

Smethie, W. M., and R. A. Fine, 2001: Rates of North Atlantic
Deep Water formation calculated from chlorofluorocarbon inventories. Deep-Sea Res., 48A, 189-215.

Spall, M., 1995: Frontogenesis, subduction, and cross-front exchange at upper ocean fronts. J. Geophys. Res., 100, 2543 2557.

- and R. Pickart, 2001: Where does dense water sink? A subpolar gyre example. J. Phys. Oceanogr., 31, 810-826.

Straneo, F., 1999: Dynamics of rotating convection including a horizontal stratification and wind. Ph.D. thesis, University of Washington, $150 \mathrm{pp}$.

_ and M. Kawase, 1999: Comparisons of localized convection due to localized forcing and preconditioning. J. Phys. Oceanogr., 29, 55-68.

_, M. Kawase, and R. Pickart, 2002: Effects of wind on convection in strongly and weakly baroclinic flows with application to the labrador sea. J. Phys. Oceanogr., 32, 2603-2618.

Visbeck, M., J. Marshall, and H. Jones, 1996: Dynamics of isolated convective regions in the ocean. J. Phys. Oceanogr., 26, 17211734 . 